\title{
A design approach to determine the shear capacity of reinforced concrete beams shear strengthened with NSM systems
}

\author{
Hadi Baghi ${ }^{1}$, Joaquim A. O. Barros ${ }^{2}$
}

\begin{abstract}
This paper present a design approach to predict the shear capacity of reinforced concrete (RC) beams strengthened with fiber reinforced polymer (FRP) laminates/rods applied according to the near surface mounted (NSM) technique. The new approach is based on the simplified modified compression field theory (SMCFT) and considers the relevant features of the interaction between NSM FRP systems and surrounding concrete, like debond and concrete fracture. In the SMCFT model, the shear strength of a RC element is a function of two parameters: the tensile stress factor in the cracked concrete $(\beta)$, and the inclination of the diagonal compressive stress in the web of the section $(\theta)$. However, this approach is not a straightforward design methodology due to its iterative nature.

A sensitivity analysis is carried out to assess the relative importance of each input parameter that mostly affect the shear capacity of RC beams shear strengthened according to the NSM technique. Taking into account the obtained results, equations to determine $\beta$ and $\theta$ without recurring to an iterative procedure are derived. The experimental results of 112 beams shear strengthened with NSM FRP are used to appraise the predictive performance of the developed approach. By evaluating the ratio between the experimental results and the analytical predictions, an average value of 1.14 is obtained, with a coefficient of variation of $13.1 \%$, being safe estimations $87 \%$ of the predictions.
\end{abstract}

Keywords: Reinforced concrete beams; Shear strengthening; Fiber Reinforced Polymer; Simplified Modified Compression Field Theory; Sensitivity Analysis; Monte Carlo simulation.

\footnotetext{
${ }^{1}$ Post-doc, Department of Civil Engineering and Construction Engineering Technology, Louisiana Tech University, Ruston, U.S., 71272-0046, e-mail: hadibaghi@ gmail.com (corresponding author).

${ }^{2}$ Full Professor, ISISE, Department of Civil Engineering, University of Minho, 4800-058, Guimarães, Portugal, email: barros@civil.uminho.pt.
} 


\section{Introduction}

The prediction of the shear capacity of reinforced concrete (RC) beams is a challenging task because shear mobilizes several complex resisting mechanisms such as: i) shear resistance assured by the uncracked concrete in the compression zone; ii) interface shear transfer by aggregate interlocking in the cracked concrete; and iii) dowel action of the longitudinal reinforcement (Bellamkonda 2013). There are two prominent approaches that have been used to predict the shear strength of RC beams with and without shear reinforcement: Truss Model (TM) and Modified Compression Field Theory (MCFT).

Truss model (TM) is based on the following two assumptions: 1) the diagonal compression struts, before and after concrete cracking are inclined at an angle of 45 degrees to the longitudinal axis of the RC member; 2) the concrete tensile strength is negligible. Hence, the truss model predicts conservative values for the ultimate shear strength of the RC elements (Blanksvärd 2009). ACI (2011) and EuroCode2 (2001) are based on the truss model. In ACI, the inclination of the concrete crack is assumed 45 degrees but does not neglect the tension in the concrete, while the EuroCode 2 neglects the tension but suggests a range of angle values for the shear crack inclination $(21.8$ and 45 degrees).

The Modified Compression Field Theory (MCFT) was developed by Vecchio and Collins (Vecchio and Collins 1986) by taking into account the resisting contribution of cracked $\mathrm{RC}$ member in tension. By applying this theory for the prediction of the shear strength of 102 panels tested experimentally, an average predictive level of 1.01 (ratio between experimental and model results), with a coefficient of variation (COV) of 12.2\%, was obtained (Bentz et al. 2006). Nevertheless, solving the equations of the MCFT to evaluate shear capacity of a RC member requires an iterative procedure and the knowledge of a relatively high number of parameters, which introduces extra difficulties in the designer perspective. AASHTO LRFD (2014) is based on MCFT model.

Bentz et al. (2006) proposed a simplified approach of the MCFT (SMCFT) method. In this model, the shear strength of a section is a function of two parameters: the tensile stress factor in the cracked concrete $(\beta)$, and the inclination of the diagonal compressive stress in the web of the section $(\theta)$. In spite of the simple format of the equations for $\beta$ and $\theta$, the method provides excellent predictions of shear strength of RC beams. By adopting the SMCFT, an average ratio of experimental to predicted shear strength of 1.11 , with a COV of $13.0 \%$, was obtained when applied to 102 RC specimens tested experimentally (Bentz et al. 2006). 
Recently, Bianco et al. (2010) suggested a new formulation to predict the contribution of near surface mounted (NSM) carbon fiber reinforced polymer (CFRP) laminates/rods for the shear strengthening of RC beams. NSM technique with CFRP laminate/rod is an effective strengthening technique for the shear strengthening of RC beams. According to this technique, slits are opened on the concrete cover of the beam's lateral faces, filled with an adhesive (in general of epoxy type), and CFRP laminate/rods are inserted into these slits (De Lorenzis and Nanni 2001, Barros and Dias 2010). This technique requires no surface preparation, and after opening the slits on the lateral concrete cover, minimum installation time is required (Barros and Dias 2010).

One of the input parameters in Bianco et al. approach is the inclination of the critical diagonal crack (CDC), $\theta$. However, due to lack of an appropriate approach to predict the $\theta$, this model gives conservative estimates of the shear strength contribution of NSM systems. This model was applied to an experimental program formed by 72 RC beams, and an average ratio of the predictions versus the experimental values of 0.69 , with a COV of $42 \%$, was obtained (Bianco et al. 2014).

In the present paper a new model is presented to predict the shear capacity of typical RC building beams shear strengthened with FRP laminates/rods applied according to the NSM technique (where crack spacing less than 300 $\mathrm{mm}$ is expected to occur). The new technique is based on the SMCFT and Bianco et al. formulations. To assess the relative importance of each input parameter that affects the shear capacity of RC beams strengthened with FRP, the tensile stress factor in cracked concrete $(\beta)$, and the inclination of the diagonal compressive stress in the web of the section $(\theta)$, a sensitivity analysis is carried out. Based on the results, equations for obtaining $\beta$ and $\theta$ without recurring to any iterative procedure were derived.

To assess the predictive performance of the proposed analytical formulation (Baghi, Barros, and Bianco (BBB)), a database (DB) composed of 112 experimental results of RC beams shear strengthened with NSM FRP systems was set from published literature. The performance of the BBB is appraised using the collected data registered in the DB.

\section{The proposed model (BBB)}

A new shear design approach is developed to predict the shear capacity of RC beams shear strengthened with FRP laminates/rods applied according to the NSM technique. The new approach is based on the SMCFT and considers the relevant features of the interaction between NSM FRP laminates/rods and surrounding concrete, like debond and concrete fracture (Baghi 2015). The new model is based on combining the formulation of NSM technique, suggested 
by Bianco et al. (Bianco et al. 2014), with the simplified MCFT, to which it is attributed the acronym BBB. According to the BBB model, the shear capacity of a NSM-FRP shear strengthened RC element is obtained from the following equation:

$$
v=v_{c}+v_{s}+v_{f}=\beta \sqrt{f_{c}^{\prime}}+\rho_{\text {sy }} f_{\text {y yield }} \cot \theta+v_{f}
$$

where $v$ is the shear stress and is assumed to be constant over the cross section, thus $v=\frac{V}{d . b_{w}}, f_{c}^{\prime}$ is the concrete compressive strength, $\rho_{s y}$ and $f_{y \text { yield }}$ are the ratio and the yield stress of the transverse steel reinforcement, respectively. $d$ and $b_{w}$ are effective depth and width of the beam, respectively. In Eq. (1), $\beta$ and $\theta$ are the tensile stress factor in the cracked concrete $(\beta)$ and the inclination of the diagonal compressive stress in the web of the section ( $\theta$ ), determined from Eq. (2) and Eq. (3), respectively.

$$
\begin{aligned}
& \beta=\frac{0.4}{1+1500 \varepsilon_{x}} \frac{1300}{1000+s_{x e}} \\
& \theta=\left(29+7000 \varepsilon_{\mathrm{x}}\right)\left(0.88+\frac{\mathrm{s}_{\mathrm{xe}}}{2500}\right) \leq 75^{\circ}
\end{aligned}
$$

where

$$
s_{x e}=\frac{35 s_{x}}{a_{g}+16} \geq 0.85 s_{x}
$$

representing physically the crack spacing, where $s_{x}$ and $a_{g}$ are the vertical distance between longitudinal reinforcement and the maximum dimension of aggregates, respectively. If the longitudinal reinforcement is not yielded, Eq. (5) can be used to calculate the $\varepsilon_{x}$ :

$$
\varepsilon_{x}=\frac{f_{s l}}{E_{s l}}=\frac{v \cot \theta-v_{c} / \cot \theta}{E_{s l} \rho_{s l}}
$$

otherwise $\varepsilon_{x}=\varepsilon_{s l y}$, where $E_{s l}, \rho_{s l}$, and $\varepsilon_{s l y}$ are the modulus of elasticity, longitudinal reinforcement ratio and yield strain of this reinforcement, while $v_{c}$ and $v$ are the shear strength of concrete and of the RC member, respectively. The shear strength contribution provided by a system of NSM FRP laminate/rod $\left(v_{f}\right)$ is determined by Bianco et al. (2014). 
Bianco et al. (2014) proposed a 3D mechanical model to predict the shear strength contribution of NSM CFRP laminates/rods. The mode of failure of an NSM FRP laminate/rod subjected to an imposed end slip can be categorized into four groups: debonding, tensile rupture of laminate, concrete semi-pyramid tensile fracture, and a mixed shallow semi-pyramid plus debonding failure mode (Fig. 1e).

During the loading process of a RC beam, when the concrete average tensile strength is attained at the bottom part of the web, some shear cracks originate, and successively progress towards the flange of the beam. These cracks can generate a single crack, Critical Diagonal Crack (CDC), with inclination of $\theta$ with respect to the beam longitudinal axis (Fig. 1a). At load step $t_{n}$, the two web parts become separated by the CDC and they start moving apart by rotating around the crack tip (point E in Fig. 1a). From that step, by increasing the applied load, the CDC opening angle $\gamma\left(t_{n}\right)$ progressively widens. The laminates that bridge the CDC offer resistance to its widening. The load imposed to the laminate, in consequence of the loaded end slip ( $\left.\delta_{L i}\right)$ evolution, is transferred by bond to the concrete surrounding the laminate along its effective bond length, $L_{f i}$ that is the shorter length between the two parts into which the crack divides its actual length. The following paragraphs introduce the formulation of this approach:

Step 1: Determine the average available resisting bond length $\left(\bar{L}_{R f i}\right)$ and the minimum integer number of FRP reinforcements that cross the $\operatorname{CDC}\left(N_{f, \text { int }}^{l}\right)$ (Fig. 1a):

$$
\begin{aligned}
& \bar{L}_{R f i}=\frac{h_{w} \sin \theta\left(\cot \theta+\cot \theta_{f}\right)}{4 \sin \left(\theta+\theta_{f}\right)} \\
& N_{f, \text { int }}^{l}=\text { round }\left[h_{w} \frac{\cot \theta+\cot \theta_{f}}{s_{f}}\right]
\end{aligned}
$$

Step 2: Evaluation of various constants (Fig. 1c and 1d):

There are three types of constants:

1) Geometric constants:

Perimeter of FRP cross section $\left(L_{p}\right)$, cross sectional area of the relevant surrounding concrete prism $\left(A_{c}\right)$, and CDC length $\left(L_{d}\right)$ :

$$
L_{p}=2 b_{f}+a_{f} ; A_{c}=s_{f} \frac{b_{w}}{2} ; L_{d}=\frac{h_{w}}{\sin \theta}
$$

2) Mechanical constants: 
The ultimate tensile force of FRP reinforcement $\left(V_{f}^{t r}\right)$, concrete average tensile strength $\left(f_{c t m}\right)$, and concrete Young's modulus $\left(E_{c}\right)$ :

$$
\begin{aligned}
& V_{f}^{t r}=a_{f} b_{f} f_{f u} \\
& f_{c t m}=0.3\left(f_{c}^{\prime}-8\right)^{2 / 3} \\
& E_{c}=9979\left(f_{c}^{\prime}\right)^{1 / 3}
\end{aligned}
$$

3) Bond-Modeling constants encompass:

Bond modeling constant $\left(J_{1}\right)$, integration constant for the softening frictional phase $\left(C_{3}\right)$, constant entering the governing differential equation for elastic phase $(\lambda)$, effective resisting bond length $\left(L_{R f e}\right)$, and maximum value of force transferable through bond by the given NSM- FRP reinforcement $\left(V_{f 1}^{b d}\right)$ :

$$
J_{1}=\frac{L_{p}}{A_{f}}\left[\frac{1}{E_{f}}+\frac{A_{f}}{A_{c} E_{c}}\right] ; C_{3}=\frac{V_{f}^{t r} J_{1}}{L_{p} \lambda} ; \frac{1}{\lambda^{2}}=\frac{\delta_{1}}{\tau_{b} J_{1}} ; L_{R f e}=\frac{\pi}{2 \lambda} ; V_{f 1}^{b d}=\frac{L_{p} \lambda \delta_{1}}{J_{1}}
$$

Step 3: Determine the reduction factor of the initial average available resisting bond length ( $\eta$ ), and equivalent value of the average resisting bond length $\left(\bar{L}_{R f i}^{e q}\right)$ :

The average resistance bond length is determined from:

$$
\bar{L}_{R f i}^{e q}=\eta \bar{L}_{R f i}
$$

where:

$$
\eta=\left\{\begin{array}{l}
\frac{f_{c t m}}{f_{c t m}^{*}} \quad \text { if } f_{c t m}<f_{c t m}^{*} \\
1 \quad \text { if } f_{c t m} \geq f_{c t m}^{*}
\end{array}\right.
$$

with:

$$
f_{c t m}^{*}=\frac{L_{p} \lambda \delta_{1} \sin \left(\lambda L_{R f i}\right)}{J_{1} \cdot \min \left(L_{R f i} \tan \alpha, b_{w} / 2\right) \cdot \min \left(s_{f} \sin \theta_{f}, 2 L_{R f i} \tan \alpha\right)}
$$

representing the concrete average tensile strength above which concrete fracture does not occur, where:

$$
L_{R f i}=\left\{\begin{array}{lll}
\bar{L}_{R f i} & \text { if } \bar{L}_{R f i} \leq L_{R f e} \\
L_{R f e} & \text { if } \bar{L}_{R f i}>L_{R f e}
\end{array}\right.
$$


Step 4: Determine the value of imposed slip in correspondence of which the maximum force transmissible by $\bar{L}_{R f i}^{e q}$ is attained $\left(V_{f i}\left(\bar{L}_{R f i}^{e q} ; \delta_{L i}\right)\right)$ :

$$
\delta_{L u}=\left\{\begin{array}{lll}
\delta_{L 1}\left(\bar{L}_{R f i}^{e q}\right) & \text { if } & V_{f 1}^{d b}<V_{f}^{t r} \\
\min \left[\delta_{L 1}\left(\bar{L}_{R f i}^{e q}\right) ; \delta_{L i}\left(V_{f}^{t r}\right)\right] & \text { if } & V_{f 1}^{d b} \geq V_{f}^{t r}
\end{array}\right.
$$

where $\delta_{L 1}\left(\bar{L}_{R f i}^{e q}\right)$ is the value of imposed end slip in correspondence of which the bond-based constitutive law $V_{f i}^{b d}\left(\bar{L}_{R f i}^{e q} ; \delta_{L i}\right)$ attains the peak value:

$$
\delta_{L 1}\left(\bar{L}_{R f i}^{e q}\right)=\left\{\begin{array}{lll}
\delta_{1}\left[1-\cos \left(\lambda \bar{L}_{R f i}^{e q}\right)\right] & \text { if } & \bar{L}_{R f i}^{e q} \leq L_{R f e} \\
\delta_{1} & \text { if } & \bar{L}_{R f i}^{e q}>L_{R f e}
\end{array}\right.
$$

and $\delta_{L i}\left(V_{f}^{t r}\right)$ is the imposed end slip in correspondence of which the strip tensile strength is attained $\left(V_{f}^{t r}\right)$ :

$$
\delta_{L i}\left(V_{f}^{t r}\right)=\delta_{1}\left\{1-\cos \left[-\arcsin \frac{C_{3}}{\delta_{1}}\right]\right\}
$$

Step 5: Determine the maximum effective shear capacity $V_{f i, \text { eff }}^{\max }$ of the NSM-FRP reinforcement with equivalent average resisting bond length $\bar{L}_{R f i}^{e q}$. The $V_{f i, e f f}^{\max }$ is evaluated by neglecting the post-peak behavior of the constitutive law:

$$
V_{f i, e f f}^{\max }=\frac{\delta_{1} A_{2}}{2 L_{d} A_{3} \gamma_{\max }}\left[\frac{\pi}{2}-\arcsin \psi-\psi \sqrt{1-\psi^{2}}\right]
$$

where:

$$
A_{2}=\frac{L_{p} \lambda}{J_{1}} ; A_{3}=\frac{\sin \left(\theta_{f}+\theta\right)}{2 \delta_{1}} ; \gamma_{\max }=\frac{2 \delta_{L u}}{L_{d} \sin \left(\theta_{f}+\theta\right)} ; \psi=1-A_{3} \cdot \gamma_{\max } \cdot L_{d}
$$

Step 6: Determine the shear strength contribution provided by a system of NSM-FRP reinforcements:

$$
\begin{aligned}
& V_{f}=2 N_{f, \text { int }}^{l} V_{f i, e f f}^{\max } \sin \theta_{f} \\
& v_{f}=2 N_{f, \text { int }}^{l} V_{f i, e f f}^{\max } \sin \theta_{f} /\left(b_{w} d\right)
\end{aligned}
$$

Figure 2 presents the solution procedure to calculate the shear strength of a $\mathrm{RC}$ beam according to the $\mathrm{BBB}$. In case of FRP rods, $a_{f}=b_{f}=\sqrt{\pi} D_{f} / 2, A_{f}=\pi D_{f}^{2} / 4$, and $L_{p}=\pi D_{f}$. The solution procedures based on BBB is available in Appendix A. 


\section{Sensitivity analysis}

Sensitivity analysis means to evaluate model output dependence (shear capacity of RC beams with and without strengthening system, Eq. (1)) on the values adopted for the input parameters $\left(h_{w}, b_{w}, a_{f}, b_{f}, s_{f}, \theta_{f}, E_{f}, f_{f u}, \alpha\right.$, $\left.\tau_{0}, \delta_{l}, f_{c}^{\prime}, a_{g}, E_{s l}, f_{y \text { yield }}, \rho_{s l}, \rho_{s y}\right)$. Sensitive analysis can be useful for a range of purposes, such as: i) model simplification; ii) searching for errors in a model; and iii) uncertainty reduction (Saltelli et al. 2008).

There are two approaches to execute sensitivity analysis. The first approach is local sensitivity analysis, which is efficient for simple cost function. Local sensitivity analysis evaluates the model output by varying one input parameter in each running keeping the other parameters fixed. In this model the influence of the interactions between parameters on the cost function is neglected (MathWorks 2015). This type of analysis is not an appropriate approach for the BBB due to the iterative nature and complexity of this model. The other approach is the global sensitivity analysis (Monte Carlo analysis) (MathWorks 2015), where the output is evaluated by varying all the input parameters simultaneously (Gilman et al. 1998).

The Monte Carlo method, also called Monte Carlo analysis, is a process of running a model numerous times with a random selection of each input parameter simultaneously. There are always some errors involved with this technique, but this error can be decreased by increasing the number of random samples. Thanks to the continuous advance of computer processors, this approach is becoming quite attractive for determining the most influencing parameters in engineering models, and how they interact.

A sensitivity analysis was carried out to assess the relative importance of each input parameter on the shear capacity of the NSM-FRP shear strengthened RC beams (Eq. (1)) in order to figure out what are the input parameters that most affect the result. Based on the previous work (Bianco et al. 2014), all of the input parameters were characterized by a uniform probability distribution, which means a range of possible values with the same likelihood of occurrence (Table 1).

For sensitivity analysis, Eq. (1) was implemented in a spreadsheet that is re-calculated two hundred thirty thousand times, each time with a set of random new possible values of the input parameters. The number of samples (230000) was adopted after some preliminary study to reduce the computational time and error simultaneously.

The dimensionless $r$ parameter, coefficient correlation, is used to measure the influence of each input parameter on the output variable (Eq. (1), $\beta$, and $\theta$ ) (Fig. 3). The $r$ is obtained from the following equation: 


$$
r=\frac{n \sum_{i=1}^{n} x_{i} y_{i}-\left(\sum_{i=1}^{n} y_{i}\right)\left(\sum_{i=1}^{n} x_{i}\right)}{\sqrt{n\left(\sum_{i=1}^{n} x_{i}^{2}\right)-\left(\sum_{i=1}^{n} x_{i}\right)^{2}} \sqrt{n\left(\sum_{i=1}^{n} y_{i}^{2}\right)-\left(\sum_{i=1}^{n} y_{i}\right)^{2}}}
$$

where $n$ is the number of the samples, $x_{i}$ is the input parameter and $y_{i}$ is output (value of BBB, $\beta$, and $\theta$ ). The $r$ parameter can varies between -1 and +1 , where + and - signs are used for positive and negative linear correlations, respectively. Positive values of $r$ indicate that when $x$ increases, $y$ also increases and when $x$ decreases, $y$ decreases. Negative values of $r$ indicate that $y$ decreases with the increase of $x$ and $y$ increases with the decrease of $x$. Finally $r$ is close to 0 when no linear correlation or a weak linear correlation exists.

According to the results presented in Fig. 3, the input parameters that most affect the value of BBB, $\beta$ and $\theta$ are the shear percentage of steel stirrups $\left(\rho_{s y}\right)$, longitudinal steel reinforcement ratio $\left(\rho_{s l}\right)$, the yield stress $\left(f_{y \text { yield }}\right)$ of steel stirrups, the concrete compressive strength $\left(f_{c}^{\prime}\right)$, ultimate tensile strength of FRP $\left(f_{f u}\right)$, and shear percentage of FRP laminates/rods $\left(\rho_{f}\right)$. As shown in Fig. 3b, the values of $\beta$ and $\theta$ are also effected by the value of the angle $(\alpha)$ between axis and generatrices of the concrete fracture surface, the beam cross-section web's depth $\left(h_{w}\right)$ and width ( $b_{w}$ ), while the value of BBB is not significantly affected by these input parameters.

Figure 4 shows the relation between $\beta$ vs $\frac{\rho_{s l} E_{s l}}{f_{c}^{\prime \prime}}$ and $\frac{\rho_{s y} f_{y y i e l d}}{f_{c}^{\prime}}+\frac{\rho_{f} f_{f u}}{f_{c}^{\prime \prime}}$ for more than 230000 generated samples with Monte Carlo simulation. In this figure, the surface that best fits the $\beta$ vs $x$ and $y$ is presented. This surface is defined by the following equation:

$$
\beta_{s}=-0.14 \times x^{0.21}+0.13 \times y^{0.15} \quad 0.05187<\beta_{s}<0.36
$$

where $x$ and $y$ are $\frac{\rho_{s y} f_{y \text { yield }}}{f_{c}^{\prime}}+\frac{\rho_{f} f_{f u}}{f_{c}^{\prime}}$ and $\frac{\rho_{s l} E_{s l}}{f_{c}^{\prime}}$, respectively. The surface is adopted after some preliminary fitting in terms of assuring surface objectivity of Goodness-of-Fit Statistics (MathWorks 2015). These statistics parameters are:

i) Sum of Squares due to Error (SSE), is the sum of the squares of residuals (Eq. 24). A small SSE indicates of tight fit of the model to the data; 


$$
\begin{aligned}
S S E= & \sum_{i=1}^{n}\left(y_{i}-f\left(x_{i}\right)\right)^{2} \\
& \text { where } f\left(x_{i}\right) \text { is the value of the adopted function (surface or line) }\left(x_{i}\right) .
\end{aligned}
$$

ii) R-square, is a number that indicates how well data fits a statistical model (Eq. 25), this statistic can take any value between 0 and 1 , where a value equal to 1 indicates that the regression line fits perfectly the data;

$$
R-\text { Square }=1-\frac{\sum_{i=1}^{n}\left(y_{i}-f\left(x_{i}\right)\right)^{2}}{\sum_{i=1}^{n}\left(y_{i}-\bar{y}\right)^{2}}
$$

where $\bar{y}$ is the mean value of $y_{i}$ :

$$
\bar{y}=\frac{1}{n} \sum_{i=1}^{n} y_{i}
$$

iii) Root Mean Squared Error (RMSE), is an estimate of the standard deviation of the random component in the data (Eq. 27); an RMSE value closer to 0 indicates of tight fit of the model to the data.

$$
R M S E=\sqrt{\frac{\sum_{i=1}^{n}\left(y_{i}-f\left(x_{i}\right)\right)^{2}}{n}}
$$

More information about these Goodness-of-Fit Statistics can be found in (MathWorks 2015). The SSE, R-square, and RMSE for this fitted surface are 466, 0.374, and 0.046, respectively. In Eq. (23) $f_{c}^{\prime}, f_{y \text { yield }}, f_{f u}, E_{s l}$ are in MPa. In this equation if the longitudinal Young's Modulus is not available, it can be assumed $200000 \mathrm{MPa}$. Furthermore, $\rho_{s y}$ , $\rho_{f}$, and $\rho_{s l}$ are introduced like ratio and not in percentage.

As mentioned, the shear strength of a concrete section is a function of $\beta$ and $\theta$. As shown in Fig. 5 for more than 230000 generated samples with Monte Carlo simulation, these two parameters are interdependent (Bentz et al. 2006; Baghi 2015). In the present work this interdependence is assumed, and Eq. (28) is suggested for obtaining $\theta_{s}$ from $\beta_{s}$ :

$$
\theta_{s}=3.36 \times \beta_{s}^{-0.82}+21.5 \quad 29^{\circ} \leq \theta_{s} \leq 60^{\circ}
$$


The SSE, R-square, and RMSE for this fitted curve are 155000, 0.9714, and 0.8354, respectively. In Fig. 4 the results are fitted for 2 variables ( $\mathrm{x}$ and $\mathrm{y}$ ), but in Fig. 5 the results are fitted for just one variable. Hence, it is reasonable the R-square value for $\beta_{s}$ is not so good as the one of $\theta_{s}$.

\section{Assessment of the predictive performance of the developed model}

A database (DB) containing 112 experiments are used to appraise the predictive performance of the developed approach (De Lorenzis and Nanni 2001; Dias 2008; Dias and Barros 2008; Islam 2009; Rizzo and De Lorenzis 2009; Dias and Barros 2010; Rahal 2010; Chaallal et al. 2011; Dias and Barros 2011; Rahal and Rumaih 2011; Dias and Barros 2013; Baghi 2015). More experiments are available in the literature, however they are not included in this database because critical parameters are missing in their description. This DB includes beams of different size, different longitudinal and transverse steel reinforcement ratios, and different NSM CFRP shear strengthening configurations and ratios. All the beams in this DB failed in shear.

The DB contains values from experiments performed on 90 beams with T cross section, and 22 beams with rectangular cross section (Fig. 6a). From 112 beams, 87 beams are shear strengthened by CFRP laminate/rod (Fig. 6b). From the 87 beams, 31 are shear strengthened with CFRP rods, and the remaining by CFRP laminates (Fig. 6c). All the collected data are reported in Table 5.

The beams tested by Dias and Barros $(2008 ; 2010 ; 2011 ; 2013)$ were of type T cross section with the same shear span to effective depth ratio (2.5), CFRP laminates, and epoxy adhesive. These beams differed on the amount of existing still stirrups ( $\rho_{s y}=0.1 \%$ and $0.17 \%$ ), percentage of longitudinal reinforcement $\left(\rho_{s l}=2.8 \%\right.$ and $\left.3.2 \%\right)$, and concrete compressive strength $\left(f_{c}^{\prime}=18.6,39.7\right.$, and $\left.31.1 \mathrm{MPa}\right)$. These series were strengthened with different configurations of NSM laminates in terms of both inclination $\theta_{f}$ and spacing $s_{f}$. However, the series V and VI of these authors (Dias 2008) were formed by beams of a higher shear aspect ratio (3.3) and concrete average compressive strength ( $\left.f_{c}^{\prime}=59.4 \mathrm{MPa}\right)$

Those beams were characterized by the following common geometric and mechanical parameters: $b_{w}=180 \mathrm{~mm} ; h_{w}=$ $300 \mathrm{~mm} ; f_{f u}=2952 \mathrm{MPa}$ (for the series I, II, III, IV) and $f_{f u}=2848 \mathrm{MPa}$ (for the series V and VI); $E_{f}=166.6 \mathrm{GPa}$ (for the series IV), $E_{f}=174.3 \mathrm{GPa}$ (for the series III, V, and VI), and $E_{f}=170.9 \mathrm{GPa}$ (for series I and II); $a_{f}=1.4$ $\mathrm{mm} ; b_{f}=9.5 \mathrm{~mm}$ (for the series I, II, III, V and VI) and $a_{f}=1.4 \mathrm{~mm} ; b_{f}=10 \mathrm{~mm}$ (for series IV). 
The beams tested by Chaallal et al. (2011) were of T cross section type, and were strengthened in shear by CFRP rods, and tested under three point bending. These beams were characterized by cross-section dimensions of $b_{w}=152 \mathrm{~mm}$ and $h_{w}=304 \mathrm{~mm}$. Concrete had average compressive strength of $25 \mathrm{MPa}$ and $35 \mathrm{MPa}$ in the series I and II, respectively. CFRP rods of $9.5 \mathrm{~mm}$ diameter, with tensile strength of $f_{f u}=1270 \mathrm{MPa}$ and modulus of elasticity of $E_{f}=148 \mathrm{GPa}$, were used.

The beams tested by De Lorenzis and Nanni (De Lorenzis and Nanni 2001) were of T cross section type, strengthened in shear with CFRP rods, and tested under four point bending. These beams were characterized by cross-section dimensions of $b_{w}=150 \mathrm{~mm}$ and $h_{w}=305 \mathrm{~mm}$. The concrete had an average compressive strength of $31 \mathrm{MPa}$. CFRP rods of nominal diameter around $9.5 \mathrm{~mm}$, with tensile strength $f_{f u}=1875 \mathrm{MPa}$ and modulus of elasticity $E_{f}=104.8$ GPa, were adopted. Two different percentages of steel stirrups were used ( $\rho_{s y}=0.0 \%$ and $\left.0.26 \%\right)$.

The beams tested by Rizzo and De Lorenzis (2009) were of rectangular cross-section type, strengthened in shear by either rods (NR) or laminates (NL), and tested under four point bending. These beams were characterized by crosssection dimensions of $b_{w}=200 \mathrm{~mm}$ and $h_{w}=210 \mathrm{~mm}$. The concrete had an average compressive strength of 29.3 MPa. Round CFRP rods of $8 \mathrm{~mm}$ diameter, with tensile strength $f_{f u}=2210 \mathrm{MPa}$ and modulus of elasticity $E_{f}=145.7$ $\mathrm{GPa}$, were used. The laminates had cross-section dimensions $a_{f}=2.0 \mathrm{~mm}$ and $b_{f}=16.0 \mathrm{~mm}$, and mechanical properties of $f_{f u}=2070 \mathrm{MPa}$ and $E_{f}=121.5 \mathrm{GPa}$.

The beams tested by Islam (2009) were of rectangular cross-section type, strengthened in shear with CFRP round rods and tested under four point bending. These beams were characterized by cross-section dimensions of $b_{w}=254 \mathrm{~mm}$ and $h_{w}=305 \mathrm{~mm}$. The concrete had an average compressive strength of $49.75 \mathrm{MPa}$. Round CFRP rods of $9 \mathrm{~mm}$ diameter, with tensile strength $f_{f u}=2070 \mathrm{MPa}$ and modulus of elasticity $E_{f}=124 \mathrm{GPa}$, were used.

The beams tested by Baghi (2015) were of rectangular and T cross-section type, strengthened in shear with CFRP laminates, and tested under three point bending. Rectangular beams were characterized by cross-section dimensions of $b_{w}=150 \mathrm{~mm}$ and $h_{w}=300 \mathrm{~mm}$, while the $\mathrm{T}$ cross section beams had a cross section dimensions of $b_{w}=180 \mathrm{~mm}$ and $h_{w}=400 \mathrm{~mm}$. In rectangular and T cross sections type of beams the length of monitored shear span, $a$, was 3.0 and 2.5 times the effective beam's depth, $d$, respectively. The concrete had an average compressive strength of 32.7 
MPa. CFRP laminates of $a_{f}=1.4 \mathrm{~mm} ; b_{f}=10 \mathrm{~mm}$, with tensile strength $f_{f u}=2620 \mathrm{MPa}$ and modulus of elasticity $E_{f}=150 \mathrm{GPa}$, were used.

The RC beams tested by Rahal (2010) and by Rahal and Rumaih (2011) were of T cross-section, and were strengthened in shear by NSM bars or steel (their label includes a letter R) or CFRP (their label includes a letter F) and tested under four point bending. These beams were characterized by T cross-section dimensions of $b_{w}=150 \mathrm{~mm}$ and $h_{w}=400 \mathrm{~mm}$. The ratio between the shear span and the beam effective depth was $a / d=3.0$. Concrete average compressive strength ranged from 36.2 MPa to 37.8 MPa. NSM FRP bars with $8 \mathrm{~mm}$ diameters, $f_{f u}=1900 \mathrm{MPa}$ and $E_{f} 124 \mathrm{GPa}$ were used.

The RC beams tested by Cisneros et al. (2012) were of rectangular cross-section strengthened in shear by either bars (their label starts by B) or laminates (their label starts by S) and tested under three point bending. The cross-section dimensions of the beams were $b_{w}=200 \mathrm{~mm}$ and $h_{w}=350 \mathrm{~mm}$. Each beam was tested twice at each end and the ratio between the shear span and the beam's effective depth was equal to $a / d=2.9$ (Fig. B.8). Concrete average compressive strength ranged from $f_{c m}=22.84 \mathrm{MPa}$ to $f_{c m}=29.11 \mathrm{MPa}$. The NSM FRP bars were characterized by 8 $\mathrm{mm}$ diameter, while the laminates had cross section dimensions of $a_{f}=2.5 \mathrm{~mm}$ and $b_{f}=15 \mathrm{~mm}$. FRP mechanical properties were $f_{f u}=2500 \mathrm{MPa}$ and $E_{f}=165 \mathrm{GPa}$.

The angle $\alpha$ is assumed equal to $28.5^{\circ}$ for all the experimental programs. To define the local bond stress-slip relationship, the following values are assumed: $\tau_{0}=20.1 \mathrm{MPa} ; \delta_{1}=7.12 \mathrm{~mm}$ (Bianco et al. 2014). When CFRP rods are used, the equivalent square cross-section is adopted in the calculations (Bianco et al. 2014). In the BBB model the aggregate size $\left(a_{g}\right)$ is assumed $25 \mathrm{~mm}$ for all the experimental programs.

For the Baghi, Barros, and Bianco (BBB) model and the new Simplified BBB model, herein designated by SBBB, the obtained values of $V_{\text {ana. }}$ are compared with $V_{\text {exp. }}$ of the $\mathrm{DB}$, and the values of the $\lambda$ factor corresponding to the $V_{\text {exp. }} / V_{\text {ana. }}$ ratio are included in Table 2 and represented in Fig. 7. In the BBB approach the average value of $V_{\text {exp. }} / V_{\text {ana. }}$ is 1.09 , with a COV of $11.0 \%$. This approach provided $82 \%$ safe estimations and $18 \%$ overestimations. The new model, SBBB, has assured an average value of $V_{\text {exp. }} / V_{\text {ana. }}$ of 1.14 with COV of $13.1 \%$, composed of $86.6 \%$ of safe estimations and $13.4 \%$ overestimations. 
A systematic trend in the error can be highlighted if the results are plotted in non-dimensional form, as it is shown in Fig. 8, where the shear resistance is normalized by a force dimensional parameter $b_{w} d f_{c}^{\prime}$. In this figure, two lines limiting to $\pm 25 \%$ the deviation of the predicted values from the experimental values are also represented, and it is verified that $91 \%$ of the results are inside of these bounds.

The values of $\lambda$ are also classified according to the modified version of the Demerit Points Classification (DPC) (Moraes Neto et al. 2014) proposed by Collins (2001), where a penalty (PEN) is assigned to each range of $\lambda$ parameter according to Table 3, and total of penalties (Total PEN) determines the performance of each analytical approach. According to the results included in Table 4, the predictive performance of BBB model is better than SBBB, since the former approach has a large number of predictions in the appropriate safety interval according to the DPC (Table 3), $\lambda \in[0.85-1.15[: 69$ samples with the BBB and 53 samples with the SBBB. However, the gain in design simplicity when SBBB is adopted seems to justify the increase in the conservative predictions ( $\lambda \in[1.15-2[): 55$ and 39 samples when using the SBBB and BBB model, respectively. It is of upmost relevance to verify that both BBB and SBBB do not have predictions on the extremely dangerous and extremely conservative intervals.

Figure 9a presents the influence of the $\rho_{s l} E_{s l} / f_{c}^{\prime}$ on the predictive performance of the studied analytical models. As shown in this figure for SBBB, the average of the $\lambda$ for R1 is in the appropriate safety interval, while for R2 and R3 is in the conservative interval. In the BBB model the $\lambda$ is in the appropriate safety interval for all the three $\mathrm{R}$ ranges of values. According to SMCFT, the large ratio of longitudinal reinforcement decreases the $\varepsilon_{x}$ (Eq. (5)), which increases $\beta$ (Eq. (2)) and decreases $\theta$ (Eq. (3)). In fact the increase of the aggregate interlock resisting mechanisms due to this effect is not modelling directly in BBB model, but indirectly through the $s_{x e}$. Hence, Fig. 9a indicates the BBB model considers the effect of $\varepsilon_{x}$ provided by longitudinal reinforcement on shear capacity of RC beams, while the SBBB is not considering so effectively the effect of the longitudinal reinforcement. The influence of $\rho_{s y} f_{y \text { yield }} / f_{c}^{\prime}$ on the $\lambda$ parameter is represented in Fig. 9b. While in the BBB an almost constant $\lambda$ parameters was obtained regardless the intervals of values adopted for $\mathrm{T}=\rho_{s y} f_{y \text { yield }} / f_{c}^{\prime}$ parameter, in the SBBB model the $\lambda$ parameter has the tendency to decrease with the increase of T. However, SBBB has only provided $\lambda$ values in the conservative interval when applied to RC without steel stirrups, therefore for current situations where a certain percentage of steel stirrups exists, the SBBB is providing $\lambda$ values in the appropriate safety interval. 
Figure $9 \mathrm{c}$ presents the average of the $\lambda$ parameter regarding to four classifications of $\mathrm{F}=\rho_{f} f_{f u} / f_{c}^{\prime}$ as defined in this figure. For F smaller than 0.3, which includes the major part of the FRP shear strengthening interventions, the $\lambda$ parameter obtained with the SBBB model is in the appropriate safety interval, while $\lambda$ values in the interval of conservative predictions are determined for $\mathrm{F}$ above 0.3 . Values of $\lambda$ in the appropriate safety interval are obtained with the BBB model for all the ranges of values considered for the F parameter.

\section{Conclusion}

In this paper, a global sensitivity analysis (Monte Carlo simulation) was carried out for deriving, from known data, the equation to determine the values for two crucial parameters of the simplified modified compression field theory (SMCFT) used to estimate the shear capacity of reinforced concrete (RC) beams, namely, the tensile stress factor in cracked concrete $(\beta)$, and the inclination of the diagonal compressive stress in the web of the section $(\theta)$. These equations were integrated into the SMCFT, which was coupled with an already published analytical formulation to derive a new approach (designated by SBBB) for the prediction of the shear capacity of RC beams shear strengthened with the near surface mounted (NSM) technique using fiber reinforcement polymer (FRP) systems.

Based on an extensive literature review regarding the shear strengthening of RC beams with FRP systems applied according to the NSM technique, a comprehensive database was assembled containing experimental results of 112 beams.

By evaluating the ratio between the experimental results and the analytical predictions ( $\lambda=V_{\text {exp. }} / V_{\text {ana. }}$ ), an average value of 1.14 , with a COV $13.1 \%$ and $87 \%$ of safe estimations were obtained by using the SBBB. The developed approach is simple of using, quite convenient for design practice, and, conceptually, it can be extended to other FRPbased shear strengthening techniques, like the externally bonded reinforcement (EBR) and the embedded through section (ETS).

\section{Appendix A}

The procedure solution for one beam strengthened with NSM CFRP laminate (2S-4LI45-I (Dias and Barros 2010), Fig. 10) is herein explained:

BBB Approach: 
Step 1: Assume a value for $\varepsilon_{x}$.

Step 2: Calculate the crack spacing based on Eq. (4).

Step 3: Calculate $\beta$ (Eq. (2)) and $\theta$ (Eq. (3)).

Step 4: Calculate the shear strength based on Eq. (1).

Step 5: Calculate the longitudinal strain (Eq. (5)), $\varepsilon_{x}$, and compare to $\varepsilon_{x}$ that was estimated in Step1. Return to Step

1 with $\varepsilon_{x}$ that has been calculated in Step 5 until $\left|\varepsilon_{x}^{q+1}-\varepsilon_{x}^{q}\right| / \varepsilon_{y \text { yield }} \leq 10^{-6}$.

This procedure solution for the 2S-4LI45-I beam is presented in Table 6 .

SBBB Approach:

Step 1: Calculate $\beta_{s}$ and $\theta_{s}$ according to Eqs. (23) and (28), respectively.

Step 2: Calculate the shear strength based on Eq. (1).

This procedure solution for the 2S-4LI45-I beam is presented in Table 7 . The inclination of the shear crack in the 2 S4LI45-I beam is presented in Fig. 11, that shows the BBB and SBBB can predict the crack inclination in reasonable accuracy.

\section{Acknowledgments}

The author acknowledges the support provided by FP7-PEOPLE-2013-ITN in the project "endure - European Network for Durable Reinforcement and Rehabilitation”, proposal MC-ITN-2013-607851.

$\begin{array}{ll}A_{f} & \text { Area of the strip's cross section } \\ A_{2} & \text { Integration constant entering the expressions to evaluate the } V_{f i, e f f}^{\max } \\ A_{3} & \text { Integration constant entering the expressions to evaluate the } V_{f i, e f f}^{\max } \\ C_{3} & \text { Integration constant for the softening friction phase } \\ D_{f} & \text { Diameter of FRP rod } \\ E_{c} & \text { Modulus of elasticity for concrete } \\ E_{f} & \text { Modulus of elasticity of FRP } \\ E_{s l} & \text { Modulus of elasticity of longitudinal reinforcement } \\ J_{1} & \text { Bond modeling constant } \\ L_{d} & \text { CDC length } \\ L_{p} & \text { Effective perimeter of the strip cross section } \\ L_{R f e} & \text { Effective resisting bond length }\end{array}$




\begin{tabular}{|c|c|}
\hline$L_{R f i}$ & $i^{t h}$ strip resisting bond length \\
\hline $\bar{L}_{R f i}^{e q}$ & Equivalent average resisting bond length \\
\hline $\bar{L}_{R f i}$ & Average available resisting bond length \\
\hline$N_{f, \text { int }}^{l}$ & Equivalent average resisting bond length \\
\hline$V$ & Shear force \\
\hline$V_{c}$ & Shear force in Concrete \\
\hline$V_{f}$ & Shear resistance contribution of fibers \\
\hline$V_{f}^{t r}$ & Strip tensile rupture capacity \\
\hline$V_{f d}$ & Design value of the NSM shear strengthening contribution \\
\hline$V_{f i, e f f}^{\max }$ & Maximum effective capacity \\
\hline$V_{f 1}^{b d}$ & Maximum value of force transferable through bond by the given FRP NSM system \\
\hline$V_{s}$ & Shear resistance contribution of steel reinforcement \\
\hline$a_{f}$ & Width of FRP laminate \\
\hline$a_{g}$ & Aggregate size \\
\hline$b_{f}$ & Thickness of FRP laminate \\
\hline$b_{w}$ & Width of strengthened cross section \\
\hline$d$ & Effective depth \\
\hline$f_{c}^{\prime}$ & Cylinder compressive strength of concrete \\
\hline$f_{c t m}^{*}$ & $\begin{array}{l}\text { Value of concrete average tensile strength for values larger than which concrete fracture does not } \\
\text { occur }\end{array}$ \\
\hline$f_{c t m}$ & Concrete average tensile strength \\
\hline$f_{f u}$ & Ultimate tensile strength of FRP \\
\hline$f_{\text {y yield }}$ & Yield stress in reinforcement \\
\hline$h_{w}$ & Beam web height \\
\hline$n$ & Number of samples \\
\hline$r$ & Coefficient correlation \\
\hline$s$ & Horizontal distance between steel stirrup \\
\hline$s_{f}$ & Spacing of NSM shear reinforcement \\
\hline$s_{x}$ & Distance between longitudinal reinforcement \\
\hline$s_{x e}$ & Effective longitudinal crack spacing \\
\hline$v$ & Shear stress \\
\hline$v_{c}$ & Shear stress in concrete \\
\hline$v_{f}$ & Shear stress in FRP laimates/rods \\
\hline$v_{s}$ & Shear stress in transverse reinforcement \\
\hline$x_{i}$ & Input parameter \\
\hline$y_{i}$ & Out put \\
\hline $\bar{y}$ & Mean value of out put \\
\hline$\alpha$ & Angle defining the concrete fracture surface \\
\hline$\beta$ & Factor accounting for the tensile stress in the cracked concrete \\
\hline$\delta_{1}$ & Slip corresponding to the end of softening friction \\
\hline$\delta_{L i}$ & Imposed slip at the loaded extremity of the $i^{\text {th }}$ strip \\
\hline$\delta_{L u}$ & $\begin{array}{l}\text { Imposed slip in correspondence of which the comprehensive peak force transmissible by } \bar{L}_{R f}^{e q} \text { is } \\
\text { attained }\end{array}$ \\
\hline
\end{tabular}


$\delta_{L 1} \quad$ Value of $\delta_{L i}$ defining the end of the first phase of the bond-based constitutive law

$\varepsilon_{f}$ Effective tensile strain in FRP reinforcement

$\varepsilon_{x} \quad$ Longitudinal strain

$\gamma_{\max }$

CDC opening angle for which the maximum effective capacity is attained

$\eta$

Reduction factor of the initial average available resisting bond length

$\lambda$

$\theta$

$\theta_{f}$

$\rho_{f}$

$\rho_{s l}$

Constant entering the governing differential equation for elastic phase

Direction of the principal stress/strain

Inclination of FRP laminates

Shear percentage of FRP laminate/rod

$\rho_{s y}$

Longitudinal steel reinforcement ratio

Transverse steel reinforcement ratio

$\tau_{0}$

Adhesive-cohesive initial bond strength

$\psi$

Constant necessary to evaluate the maximum effective capacity provided by the equivalent average resisting bond length

\section{References:}

AASHTO, L. R. F. D. (2014). Bridge Design Specifications., American Association of State Highway and Transportation Officials.

ACI Committee \& International Organization for Standardization (2011). Building code requirements for structural concrete (ACI 318-08) and commentary, American Concrete Institute.

Baghi, H. (2015). The effectivness of SHCC-FRP panles of the shear resistance of RC beams. PhD Thesis, University of Minho.

Bellamkonda, S. A. (2013). Modeling of Shear Strengthening of Reinforced Concrete Beams Retrofitted with Externally Bonded Fiber Reinforced Polymers. Master Thesis, Louisiana State University.

Bentz, E. C., Vecchio, F.J., and Collins, M.P. (2006). "Simplified Modified Compression Field Theory for Calculating Shear Strength of Reinforced Concrete Elements." ACI STRUCTURAL JOURNAL 103: 614-624.

Bianco, V., Barros, J.A.O., and Monti, G. (2010). "New approach for modeling the contribution of NSM FRP strips for shear strengthening of RC beams." ASCE Composites for Construction Journal 14(1): 36-48.

Bianco, V., Monti, G., and Barros, J.A.O. (2014). "Design formula to evaluate the NSM FRP strips shear strength contribution to a RC beam." Composites Part B: Engineering 56: 960-971.

Blanksvärd, T. (2009). Strengthening of concrete structures by the use of mineralbased composites. PhD Thesis, Luleå University of Technology. 
British Standards Institution (2001). Eurocode 2: Design of Concrete Structures: Part 1-1: General Rules and Rules for Buildings, British Standards Institution.

Chaallal, O., Mofidi, A., Benmokrane, B., and Neale, K. (2011). "Embedded Through-Section FRP Rod Method for Shear Strengthening of RC Beams: Performance and Comparison with Existing Techniques." Composites for Construction 19: 374-383.

Cisneros, D., Arteaga, A., De Diego, A., Alzate, A., and Perera, R. (2012). Experimental Study on NSM shear retrofiting of RC beams. 6th international conference on Composites in Civil Engineering, CICE 2012. Rome, Italy.

Collins, M. P. (2001). Evaluation of shear design procedures for concrete structures. A Report prepared for the CSA technical committee on reinforced concrete design.

De Lorenzis, L. and Nanni, A. (2001). "Shear Strengthening of Reinforced Concrete Beams with Near-Surface Mounted Fiber-Reinforced Polymer Rods." ACI Structural Journal 98: 60-68.

Dias, S. J. E. (2008). Experimental and anlytical research in the shear strengthening of reinforced concreet beams using the near surface mounted technique with CFRP strips. PhD Thesis, University of Minho, GuimarãesPortugal, in Portugese.

Dias, S. J. E., and Barros, J.A.O. (2011). "Shear strengthening of RC T-section beams with low concrete using NSM CFRP laminates." Journal Cement \& Concrete Composites 3(2): 334-345.

Dias, S. J. E. and Barros, J.A.O. (2008). "Shear Strengthening of T Cross Section Reinforced Concrete Beams by Near Surface Mounted Technique." Journal of Composites for Construction, ASCE 12(No.3): 300-311.

Dias, S. J. E. and Barros, J.A.O. (2010). "Performance of reinforced concrete T beams strengthened in shear with NSM CFRP laminates." Engineering Structures 32: 373-384.

Dias, S. J. E. and Barros, J.A.O. (2013). "Shear strengthening of RC beams with NSM CFRP laminates: Experimental research and analytical formulation." Composite Structures 99: 477-490.

Gilman, J. R., Brickey, R.T., and Red, M.M. (1998). Monte Carlo Techniques for Evaluating Producing Properties, Society of Petroleum Engineers.

Islam, A. A. (2009). "Effective methods of using CFRP bars in shear strengthening of concrete girders." Engineering Structures 31: 709-714.

MathWorks, (2015). What Is Sensitivity Analysis? 
Moraes Neto, B., Barros, J., and Melo, G. (2014). "Model to Simulate the Contribution of Fiber Reinforcement for the Punching Resistance of RC Slabs." Journal of Materials in Civil Engineering 26(7).

Rahal, K. N. (2010). "Near surface mounted shear strengthening of reinforced concrete beams." American Concrete Institute (ACI), Special Publication SP-272-13: 251-268.

Rahal, K. N. and Rumaih, Hantem A. (2011). "Tests on reinforced concrete beams strengthened in shear using near surface mounted CFRP and steel bars." Engineering Structures 33: 53-62.

Rizzo, A. and De Lorenzis, L. (2009). "Behaviour and capacity of RC beams strengthened in shear with NSM FRP reinforcement." Construction and Building Materials 3(No.4): 1555-1567.

Saltelli et al. (2008). " Global Sensitivity Analysis ", John Wiley and Sons.

Vecchio, F. J., Collins, M.P. (1986). "The Modified Compression-Field Theory for Reinforced Concrete Elements Subjected to Shear." ACI Journal: 219-231. 

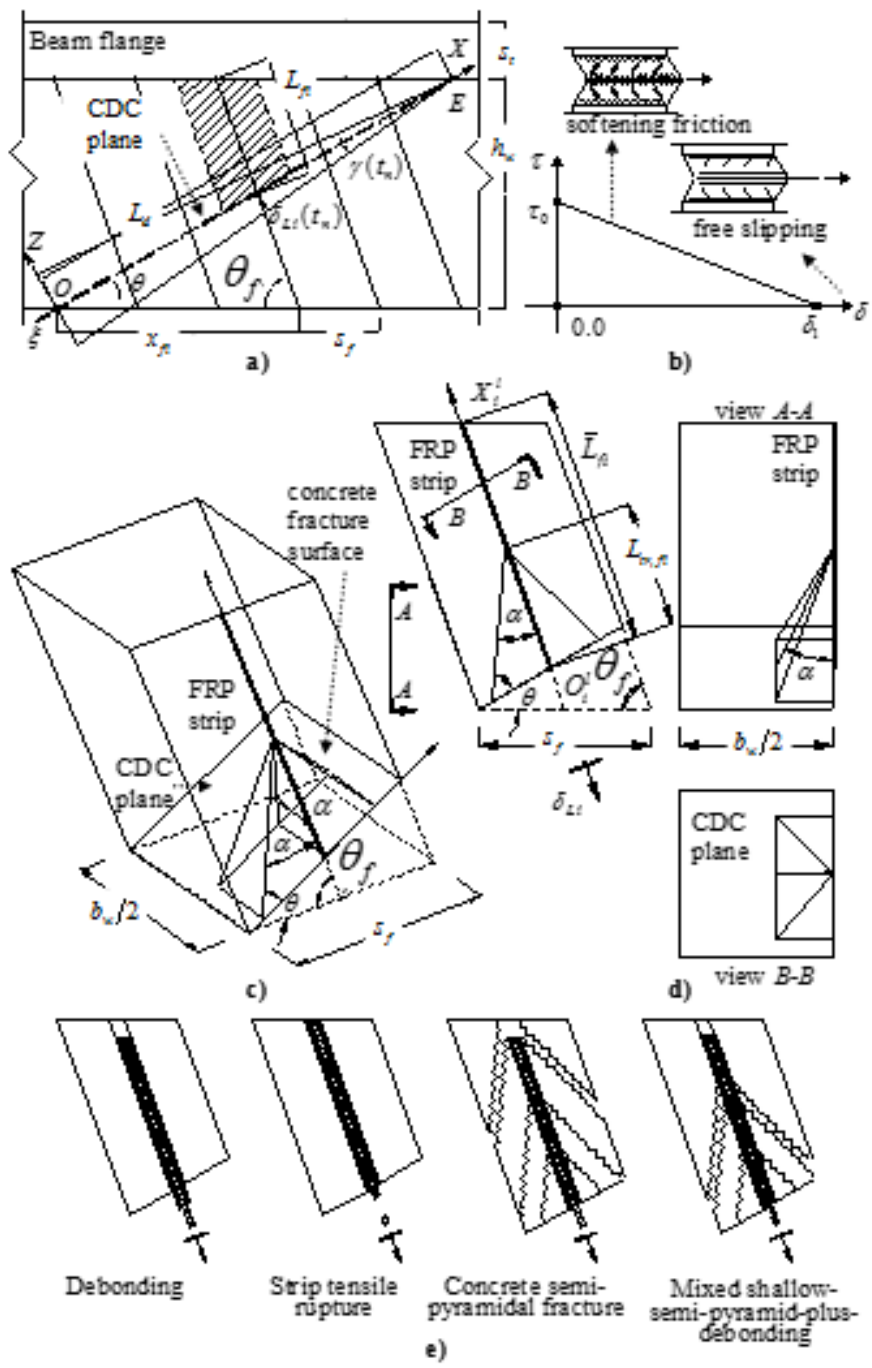

Fig. 1: Schematic representation of the Bianco et al. (2014) approach; a) average-available-bond-length NSM strip and concrete prism of influence; b) adopted local bond stress-slip relationship; c) NSM strip confined to the corresponding concrete prism of influence and semi-pyramidal fracture surface; d) sections of the concrete prism; e) The mode of failure of an NSM FRP laminate subjected to an imposed end slip. 


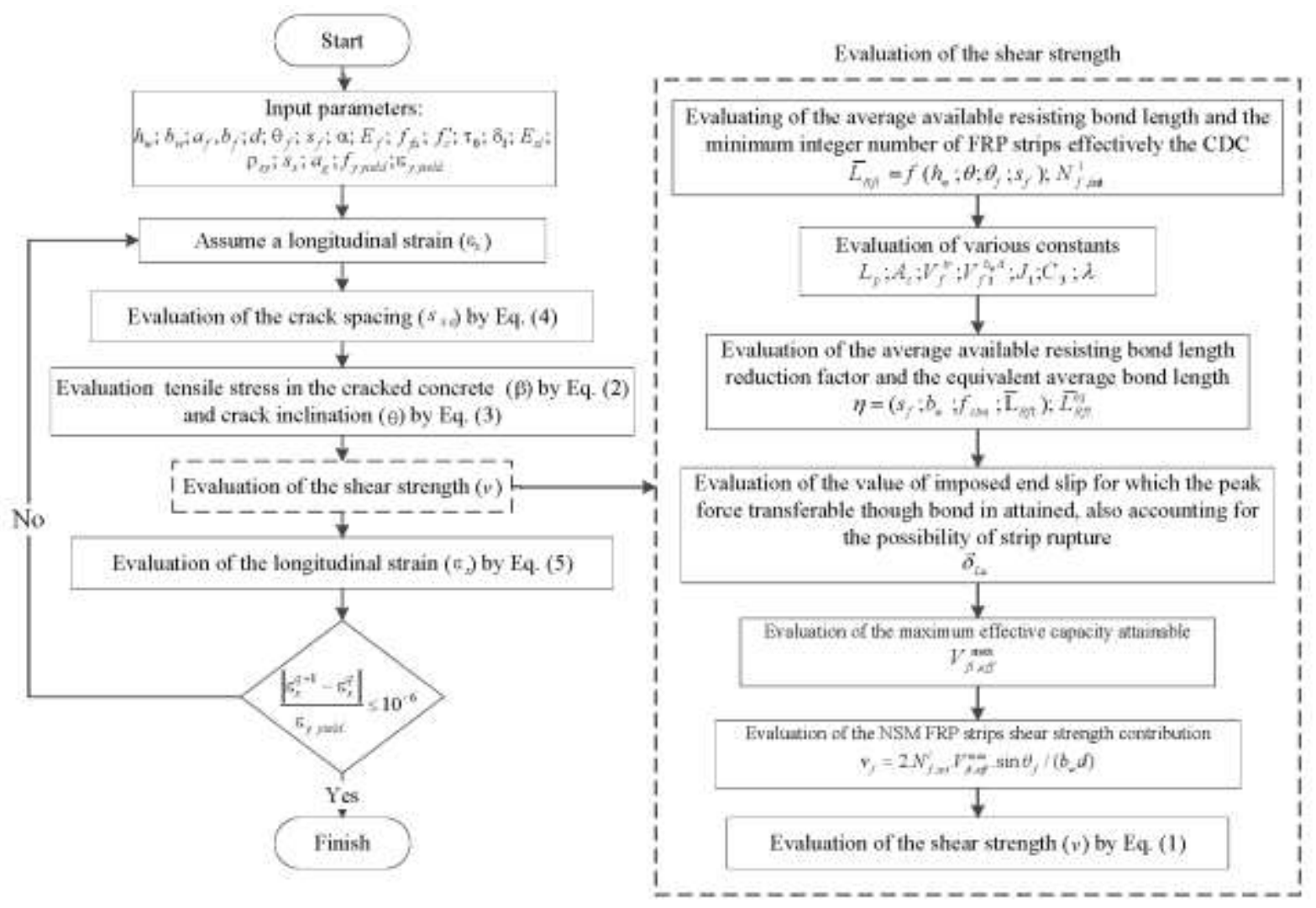

Fig. 2: Calculation procedure of BBB model 


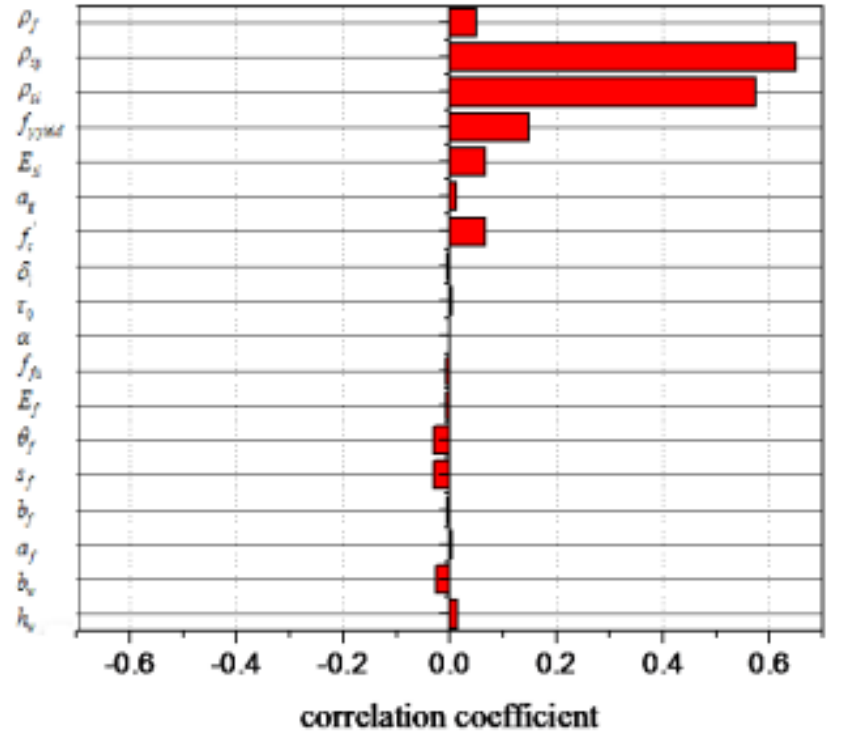

a)

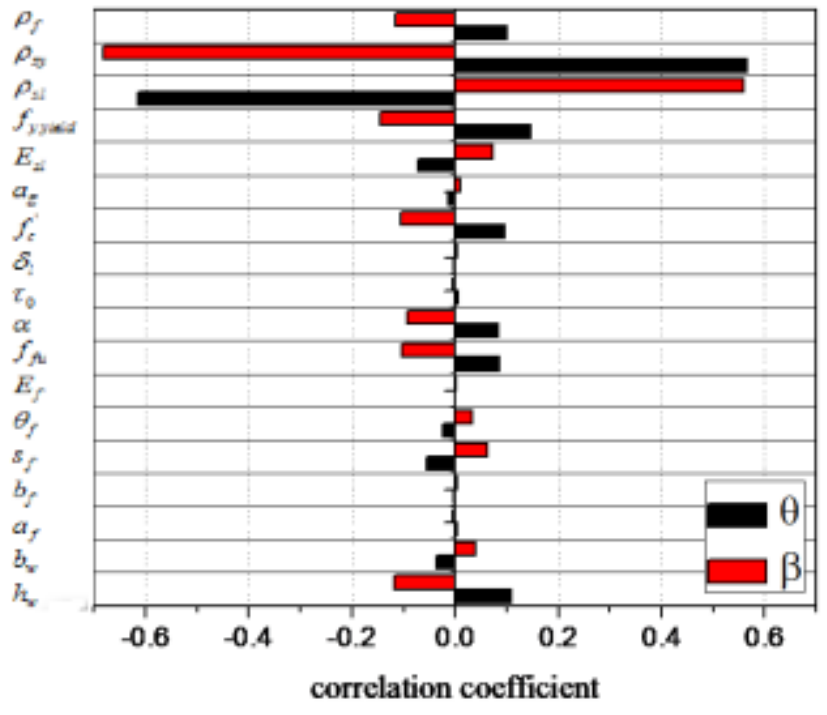

b)

Fig. 3: Sensitivity analysis for a) BBB; b) the tensile stress in the cracked concrete ( $\beta$ ); and the inclination of the diagonal compressive stress in the web of the section $(\theta)$ 


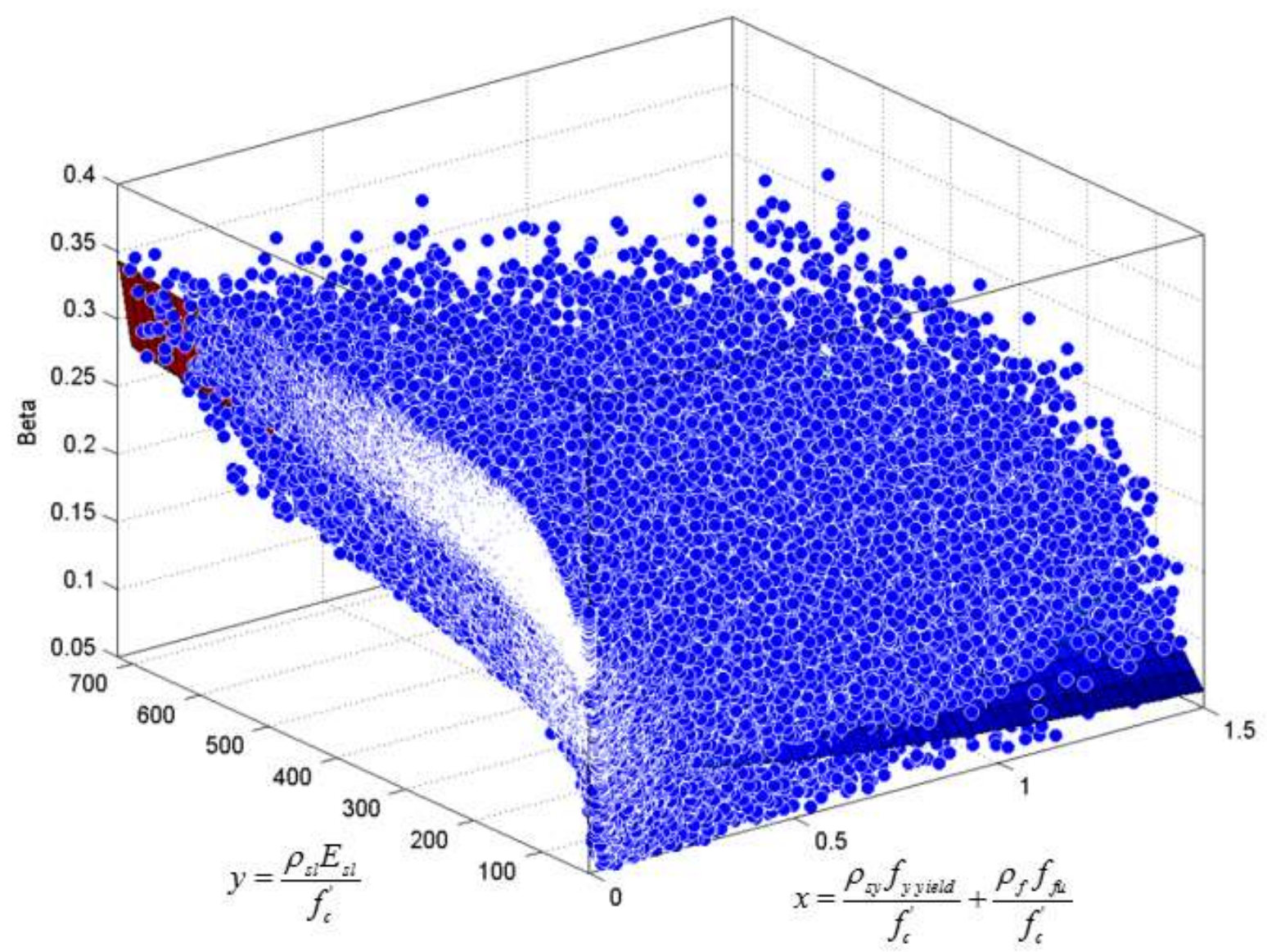

Fig. 4: Results of Monte Carlo simulation 


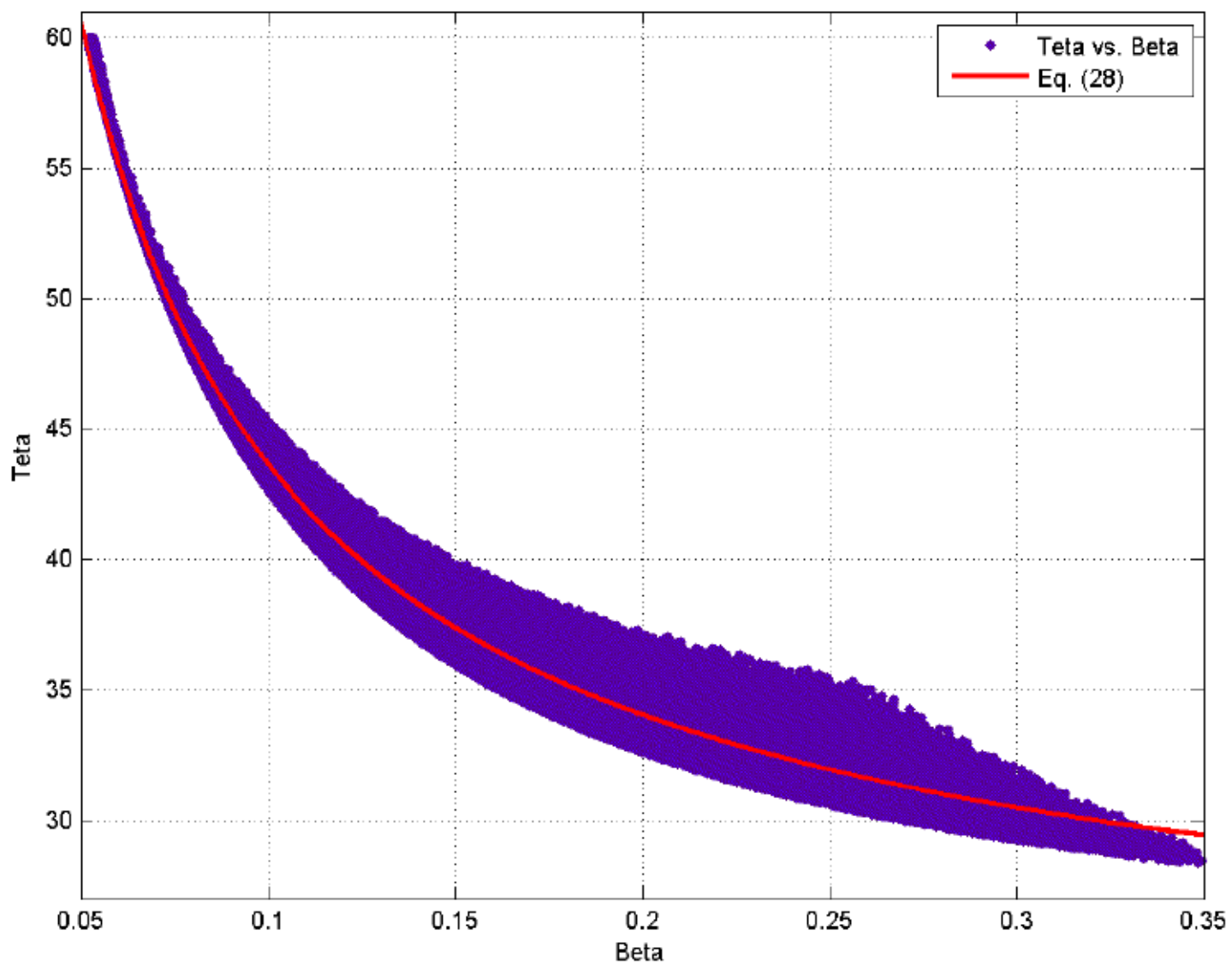

Fig. 5: Relation between $\theta_{s}$ and $\beta_{s}$ (Eq. (28)) 

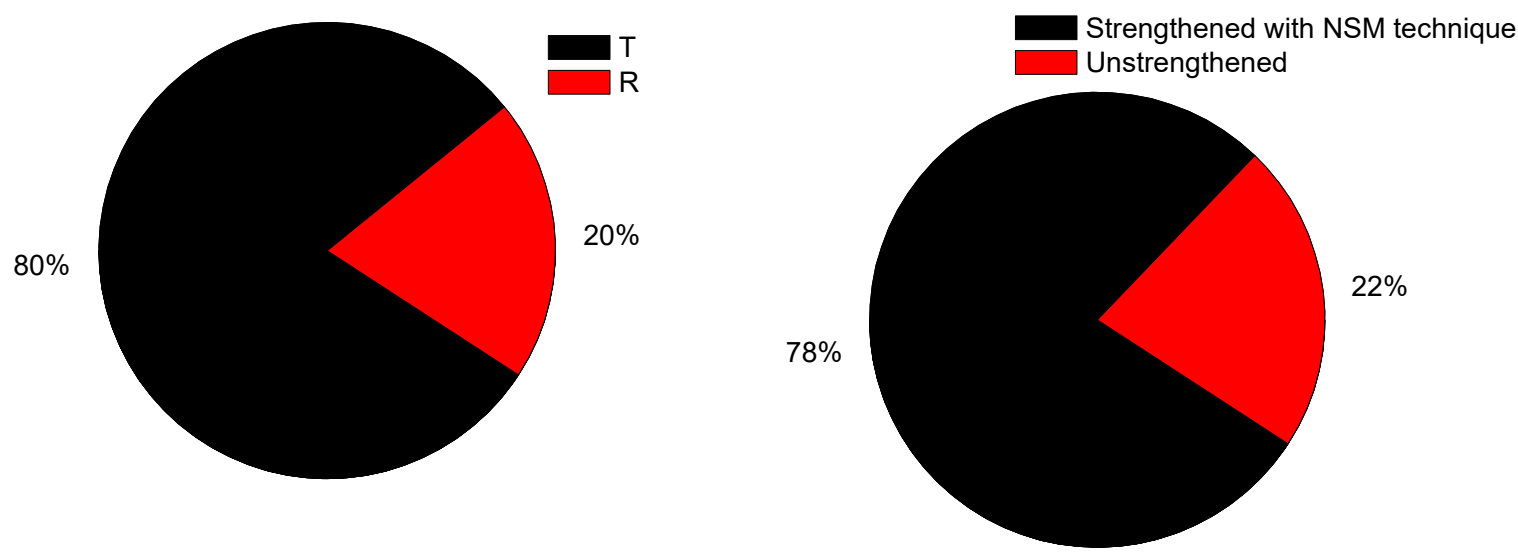

a) Distribution of rectangular and $\mathrm{T}$ cross section beams

b) Distribution of strengthened beams

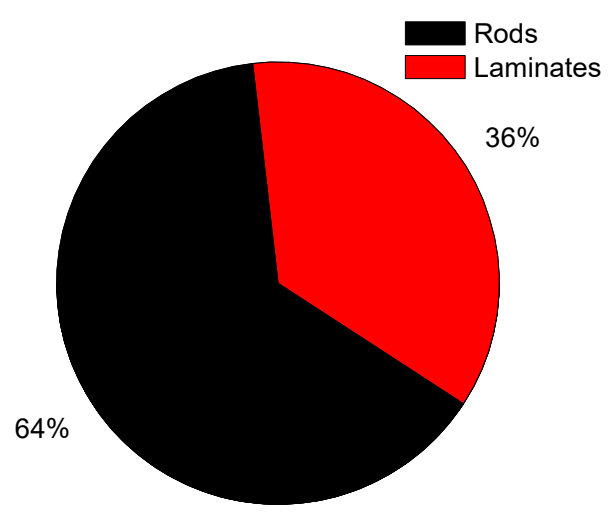

c) Distribution of strengthened beams with FRP laminates and rods

Fig. 6: Characteristics of the database 


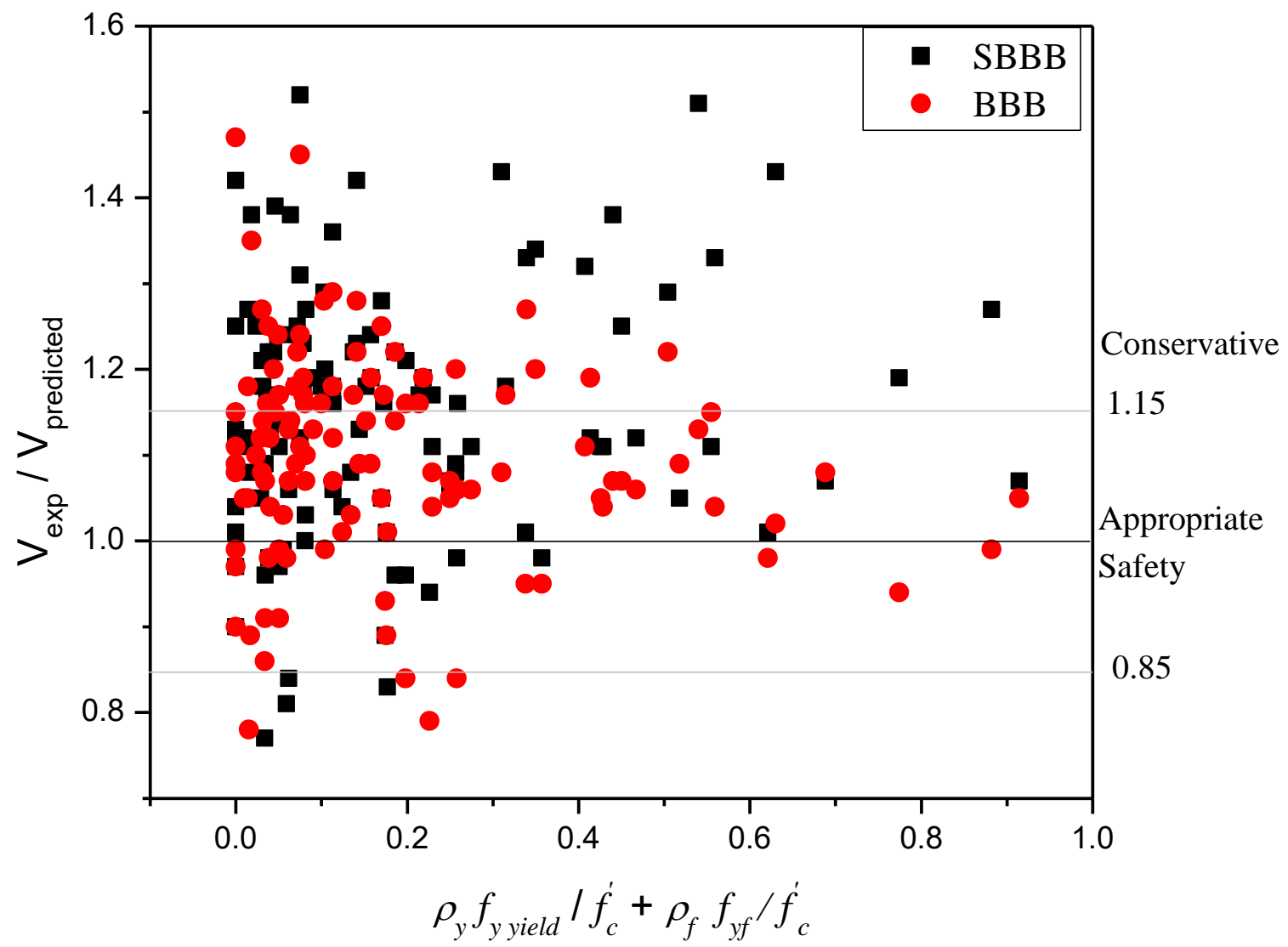

Fig. 7: Ratio between experimental and analytical model 


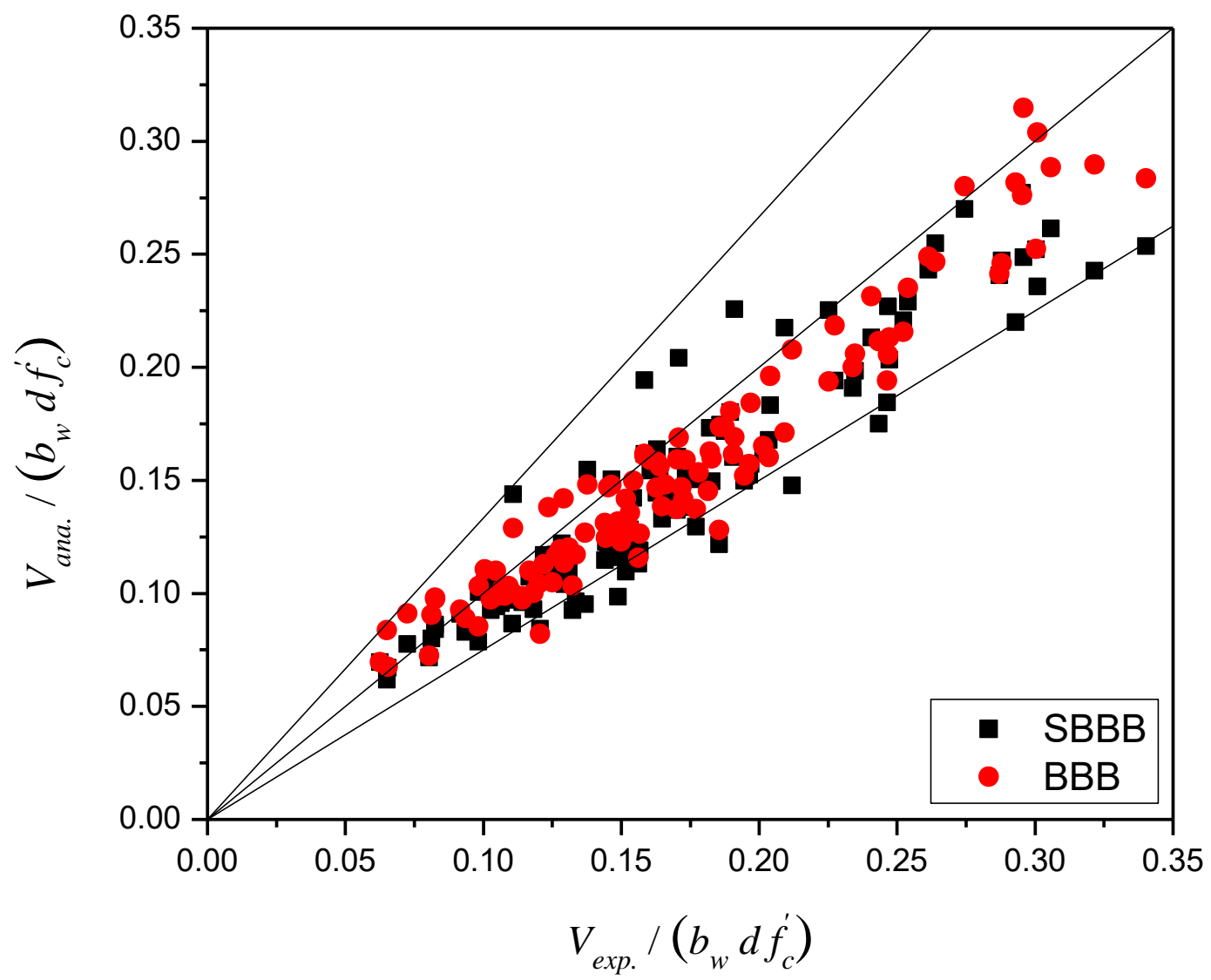

Fig. 8: Predicted non-dimensional shear failure force of the RC beams DB, in comparison with experimental values 

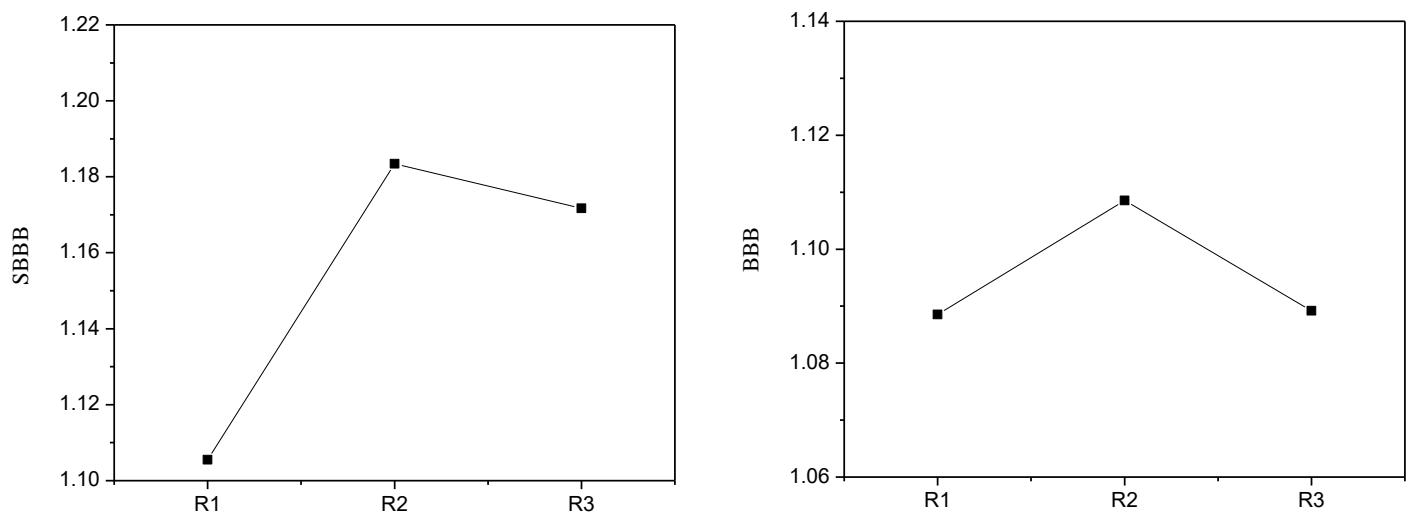

a) $50 \leq \mathrm{R} 1<150$ ( 47 beams); $150 \leq \mathrm{R} 2<250$ (41 beams); $\mathrm{R} 3 \geq 250$ ( 24 beams)
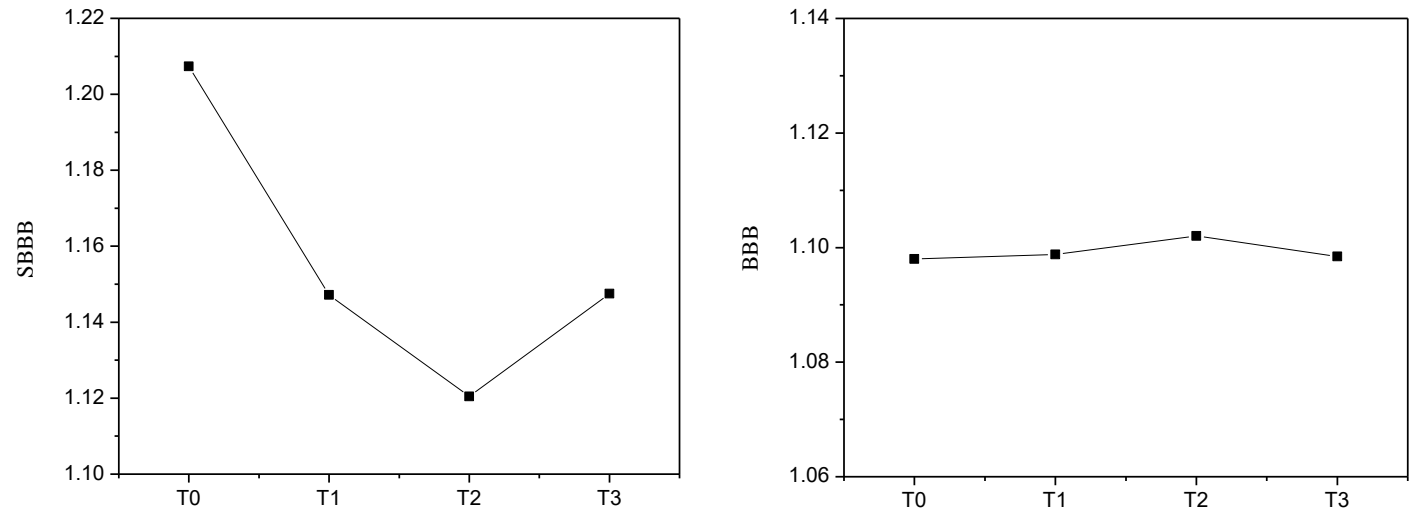

b) $\mathrm{T} 0=0$ ( 15 beams); $0.0<\mathrm{T} 1<0.015$ ( 25 beams); $0.015 \leq \mathrm{T} 2<0.03$ ( 44 beams); $\mathrm{T} 3 \geq 0.03$ ( 28 beams $)$
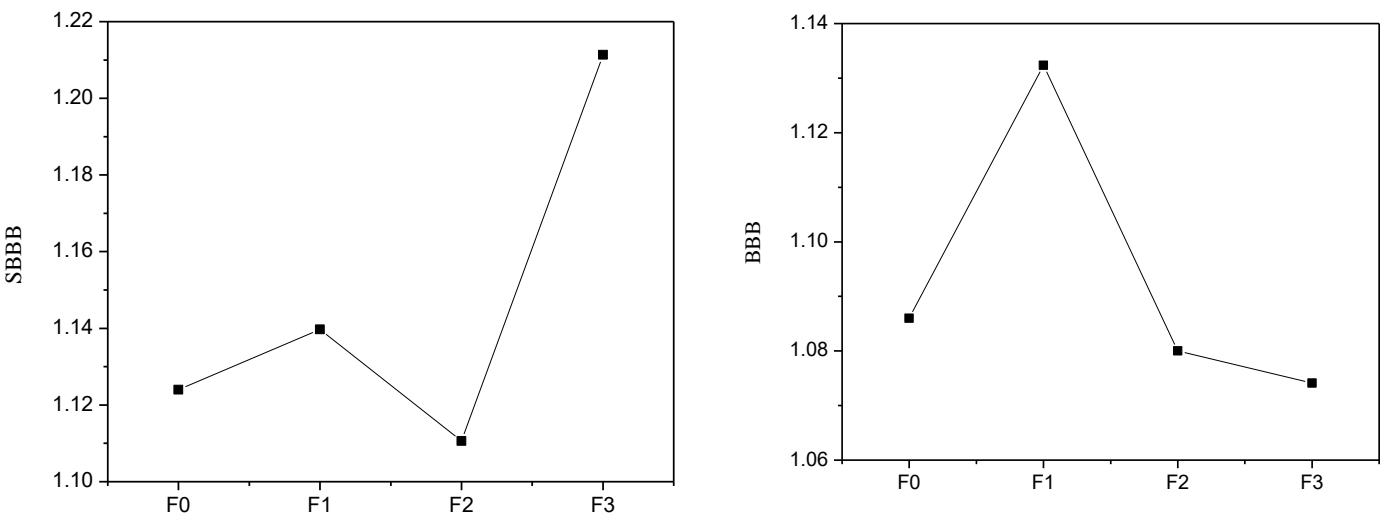

c) $\mathrm{F} 0=0$ ( 25 beams); $0.0<\mathrm{F} 1<0.1$ ( 34 beams); $0.1 \leq \mathrm{F} 2<0.3$ ( 31 beams); $\mathrm{F} 3 \geq 0.3$ ( 22 beams)

Fig. 9: Influence of the: a) $\mathrm{R}=\rho_{s l} E_{s l} / f_{c}^{\prime}$; b) $\mathrm{T}=\rho_{s y} f_{\text {yyield }} / f_{c}^{\prime}$; and c) $\mathrm{F}=\rho_{f} f_{f u} / f_{c}^{\prime}$ on the predictive performance of the models 

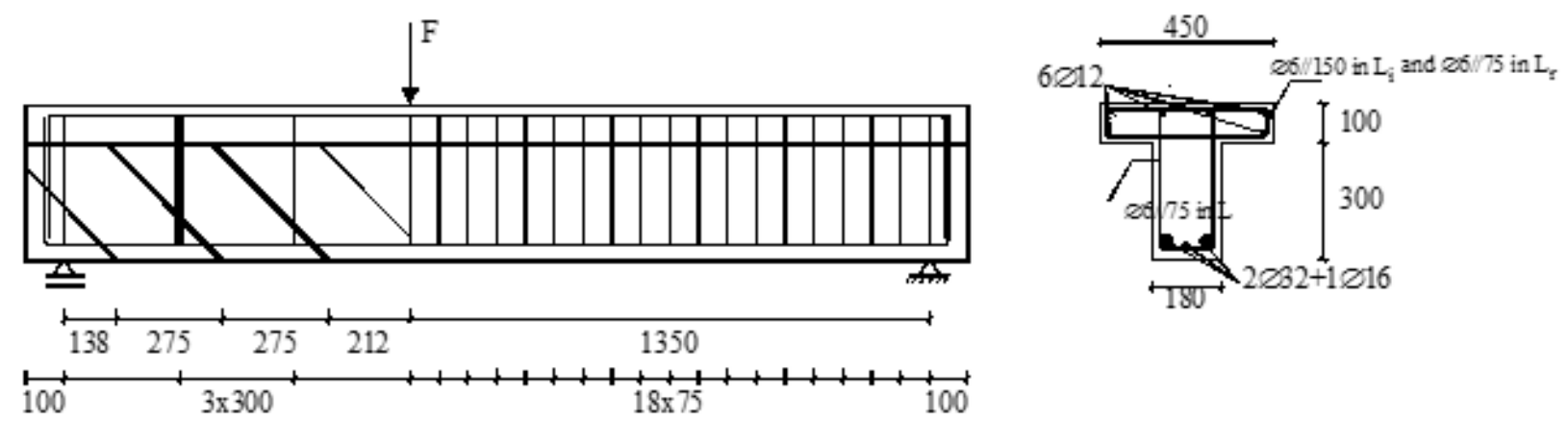

Fig. 10: geometry of the beam 2S-4LI45-I 


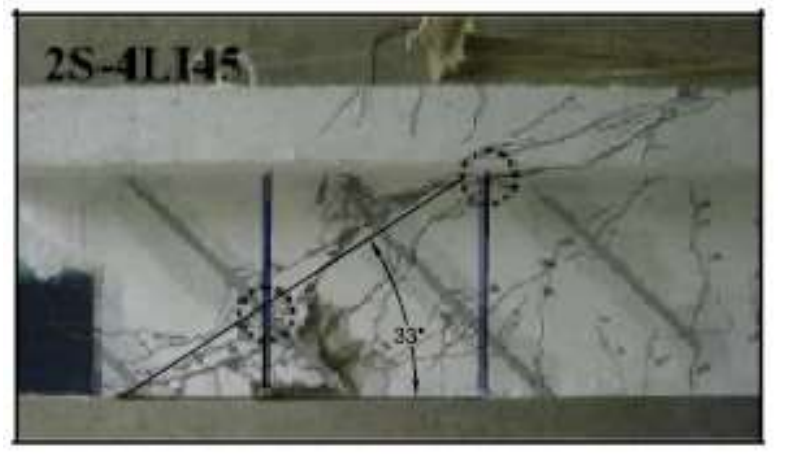

Fig. 11: Crack inclination in 2S-4LI45-I beam 
Table 1: Values characterizing the uniform probability distribution of the input parameters.

Table 2: Summary of experimental and analytical results applied to the DB

Table 3: Demerit points classification criteria

Table 4: Predictive performance of different approaches according to the modified version of the DPC

Table 5: Geometrical and mechanical data of the experimental RC beams

Table 6: BBB approach

Table 7: SBBB approach 
Table 1: Values characterizing the uniform probability distribution of the input parameters.

\begin{tabular}{|c|c|c|c|c|c|c|c|c|c|c|c|c|c|c|c|c|c|}
\hline & $\begin{array}{c}h_{w} \\
m m\end{array}$ & $\begin{array}{c}b_{w} \\
m m\end{array}$ & $\begin{array}{c}a_{f} \\
m m\end{array}$ & $\begin{array}{c}b_{f} \\
m m\end{array}$ & $\begin{array}{c}s_{f} \\
m m\end{array}$ & $\begin{array}{c}\theta_{f} \\
\circ\end{array}$ & $\begin{array}{c}E_{f} \\
G P a\end{array}$ & $\begin{array}{c}f_{f u} \\
G P a\end{array}$ & $\begin{array}{r}\alpha \\
\circ\end{array}$ & $\begin{array}{c}\tau_{0} \\
M P a\end{array}$ & $\begin{array}{c}\delta_{1} \\
m m\end{array}$ & $\begin{array}{c}f_{c}^{\prime} \\
M P a\end{array}$ & $\begin{array}{c}a_{g} \\
m m\end{array}$ & $\begin{array}{c}E_{s l} \\
G P a\end{array}$ & $\begin{array}{l}f_{y \text { yield }} \\
M P a\end{array}$ & $\begin{array}{c}\rho_{s l} \\
(\%)\end{array}$ & $\begin{array}{l}\rho_{s y} \\
(\%)\end{array}$ \\
\hline $\begin{array}{l}\text { Range of } \\
\text { variation }\end{array}$ & $\begin{array}{l}200- \\
700\end{array}$ & $\begin{array}{r}150- \\
400\end{array}$ & $\begin{array}{l}1.0- \\
5.5\end{array}$ & $\begin{array}{l}5- \\
35\end{array}$ & $\begin{array}{l}50- \\
300\end{array}$ & $\begin{array}{l}30- \\
90\end{array}$ & $\begin{array}{l}100- \\
200\end{array}$ & $\begin{array}{l}1.0- \\
4.0\end{array}$ & $\begin{array}{l}10- \\
35\end{array}$ & $\begin{array}{l}10- \\
30\end{array}$ & \begin{tabular}{||l}
$2.0-$ \\
15.
\end{tabular} & $\begin{array}{l}15- \\
90\end{array}$ & $\begin{array}{l}10- \\
40\end{array}$ & $\begin{array}{l}180- \\
220\end{array}$ & $\begin{array}{l}300- \\
700\end{array}$ & $1-4$ & $\begin{array}{l}0- \\
1.8\end{array}$ \\
\hline
\end{tabular}


Table 2: Summary of experimental and analytical results applied to the DB

\begin{tabular}{|c|c|c|c|c|c|c|c|c|}
\hline \multirow[b]{2}{*}{ Beam Label } & \multirow[b]{2}{*}{$\begin{array}{c}f_{c}^{\prime} \\
(\mathrm{MPa})\end{array}$} & \multicolumn{4}{|c|}{ Reinforcement } & \multirow[b]{2}{*}{$\begin{array}{l}V_{\text {exp. }} \\
(\mathrm{kN})\end{array}$} & \multirow[b]{2}{*}{$\frac{V_{\text {exp. }}}{V_{S B B B}}$} & \multirow[b]{2}{*}{$\frac{V_{\text {exp. }}}{V_{B B B}}$} \\
\hline & & $\frac{\rho_{s l} E_{s l}}{f_{c}^{\prime}}$ & $\theta_{f}$ & $\frac{\rho_{\text {sy }} f_{\text {y yield }}}{f_{c}^{\prime}}$ & $\frac{\rho_{f} f_{f u}}{f_{c}^{\prime}}$ & & & \\
\hline \multicolumn{9}{|c|}{ Dias and Barros $(2010 ; 2013)$} \\
\hline$C-R-I$ & \multirow{19}{*}{39.7} & \multirow{19}{*}{146.7} & - & 0 & 0 & 207 & 1.12 & 1.11 \\
\hline $2 S-R-I$ & & & - & 0.0143 & 0 & 304 & 1.27 & 1.18 \\
\hline $7 S-R-I$ & & & - & 0.038 & 0 & 467 & 1.22 & 1.25 \\
\hline $2 S-4 L V-I$ & & & $90^{\circ}$ & 0.0143 & 0.056 & 337 & 1.18 & 1.09 \\
\hline $2 S-7 L V-I$ & & & $90^{\circ}$ & 0.0143 & 0.09 & 374 & 1.20 & 0.99 \\
\hline $2 S-10 L V-I$ & & & $90^{\circ}$ & 0.0143 & 0.12 & 397 & 1.08 & 1.03 \\
\hline $2 S-4 L I 45-I$ & & & $45^{\circ}$ & 0.0143 & 0.055 & 393 & 1.24 & 1.18 \\
\hline $2 S-7 L I 45-I$ & & & $45^{\circ}$ & 0.0143 & 0.09 & 422 & 1.07 & 1.05 \\
\hline $2 S-10 L I 45-I$ & & & $45^{\circ}$ & 0.0143 & 0.13 & 446 & 1.13 & 1.09 \\
\hline $2 S-4 L I 60-I$ & & & $60^{\circ}$ & 0.0143 & 0.049 & 386 & 1.29 & 1.22 \\
\hline $2 S-6 L I 60-I$ & & & $60^{\circ}$ & 0.0143 & 0.076 & 394 & 1.19 & 1.13 \\
\hline $2 S-9 L I 60-I$ & & & $60^{\circ}$ & 0.0143 & 0.11 & 413 & 1.04 & 1.01 \\
\hline $4 S-R-I I$ & & & - & 0.0237 & 0 & 371 & 1.25 & 1.10 \\
\hline $4 S-4 L V-I I$ & & & $90^{\circ}$ & 0.0237 & 0.055 & 424 & 1.23 & 1.19 \\
\hline $4 S-7 L V-I I$ & & & $90^{\circ}$ & 0.0237 & 0.09 & 427 & 1.16 & 1.12 \\
\hline $4 S-4 L I 45-I I$ & & & $45^{\circ}$ & 0.0237 & 0.055 & 442 & 1.18 & 1.17 \\
\hline $4 S-7 L I 45-I I$ & & & $45^{\circ}$ & 0.0237 & 0.09 & 478 & 1.06 & 1.07 \\
\hline $4 S-4 L I 60-I I$ & & & $60^{\circ}$ & 0.0237 & 0.048 & 444 & 1.25 & 1.22 \\
\hline $4 S-6 L I 60-I I$ & & & $60^{\circ}$ & 0.0237 & 0.076 & 458 & 1.18 & 1.16 \\
\hline \multicolumn{9}{|c|}{ Dias and Barros (2011) } \\
\hline$C-R-I I I$ & 18.6 & 313.1 & - & 0 & 0 & 147 & 1.04 & 1.08 \\
\hline
\end{tabular}




\begin{tabular}{|c|c|c|c|c|c|c|c|c|}
\hline $2 S-R-I I I$ & & & - & 0.0304 & 0 & 226 & 1.09 & 1.08 \\
\hline $4 S-R-I I I$ & & & - & 0.0508 & 0 & 304 & 1.14 & 1.17 \\
\hline $2 S-7 L V-I I I$ & & & $90^{\circ}$ & 0.0304 & 0.199 & 274 & 1.17 & 1.04 \\
\hline $2 S-4 L I 45-I I I$ & & & $45^{\circ}$ & 0.0304 & 0.122 & 283 & 1.18 & 1.14 \\
\hline $2 S-7 L I 45-I I I$ & & & $45^{\circ}$ & 0.0304 & 0.199 & 306 & 1.11 & 1.08 \\
\hline $2 S-4 L I 60-I I I$ & & & $60^{\circ}$ & 0.0304 & 0.107 & 282 & 1.22 & 1.17 \\
\hline $2 S-6 L I 60-I I I$ & & & $60^{\circ}$ & 0.0304 & 0.168 & 298 & 1.21 & 1.16 \\
\hline $4 S-7 L V-I I I$ & & & $90^{\circ}$ & 0.0508 & 0.199 & 315 & 1.07 & 1.05 \\
\hline $4 S-4 L I 45-I I I$ & & & $45^{\circ}$ & 0.0508 & 0.122 & 347 & 1.16 & 1.17 \\
\hline $4 S-7 L I 45-I I I$ & & & $45^{\circ}$ & 0.0508 & 0.199 & 356 & 1.06 & 1.07 \\
\hline $4 S-4 L I 60-I I I$ & & & $60^{\circ}$ & 0.0508 & 0.107 & 346 & 1.19 & 1.19 \\
\hline $4 S-6 L I 60-I I I$ & & & $60^{\circ}$ & 0.0508 & 0.168 & 362 & 1.19 & 1.19 \\
\hline \multicolumn{9}{|c|}{ Dias and Barros (2008) } \\
\hline$C-R-I V$ & \multirow{12}{*}{31.1} & \multirow{12}{*}{193.9} & - & 0 & 0 & 243 & 1.42 & 1.47 \\
\hline $2 S-R-I V$ & & & - & 0.0182 & 0 & 315 & 1.38 & 1.35 \\
\hline $6 S-R-I V$ & & & - & 0.0303 & 0 & 410 & 1.21 & 1.27 \\
\hline $2 S-3 L V-I V$ & & & $90^{\circ}$ & 0.0182 & 0.057 & 316 & 1.31 & 1.24 \\
\hline $2 S-5 L V-I V$ & & & $90^{\circ}$ & 0.0182 & 0.095 & 357 & 1.36 & 1.29 \\
\hline $2 S-8 L V-I V$ & & & $90^{\circ}$ & 0.0182 & 0.152 & 396 & 1.28 & 1.25 \\
\hline $2 S-3 L I 45-I V$ & & & $45^{\circ}$ & 0.0182 & 0.057 & 328 & 1.12 & 1.11 \\
\hline $2 S-5 L I 45-I V$ & & & $45^{\circ}$ & 0.0182 & 0.095 & 384 & 1.18 & 1.18 \\
\hline $2 S-8 L I 45-I V$ & & & $45^{\circ}$ & 0.0182 & 0.152 & 382 & 1.05 & 1.05 \\
\hline $2 S-3 L I 60-I V$ & & & $60^{\circ}$ & 0.0182 & 0.057 & 374 & 1.52 & 1.45 \\
\hline $2 S-5 L I 60-I V$ & & & $60^{\circ}$ & 0.0182 & 0.085 & 392 & 1.29 & 1.28 \\
\hline $2 S-7 L I 60-I V$ & & & $60^{\circ}$ & 0.0182 & 0.123 & 406 & 1.23 & 1.22 \\
\hline \multicolumn{9}{|c|}{ Dias (2008) } \\
\hline$C-R-V$ & 59.4 & 108.6 & - & 0 & 0 & 252 & 0.97 & 0.97 \\
\hline
\end{tabular}




\begin{tabular}{|c|c|c|c|c|c|c|c|c|}
\hline $3 S-R-V$ & & & - & 0.0095 & 0 & 360 & 1.12 & 1.05 \\
\hline $3 S-6 L V-V$ & & & $90^{\circ}$ & 0.0095 & 0.025 & 387 & 0.96 & 0.91 \\
\hline $3 S-10 L V-V$ & & & $90^{\circ}$ & 0.0095 & 0.041 & 497 & 1.11 & 0.91 \\
\hline $3 S-5 L I 45-V$ & & & $45^{\circ}$ & 0.0095 & 0.025 & 492 & 1.09 & 1.07 \\
\hline $3 S-9 L I 45-V$ & & & $45^{\circ}$ & 0.0095 & 0.041 & 564 & 0.97 & 0.99 \\
\hline $3 S-5 L I 60-V$ & & & $60^{\circ}$ & 0.0095 & 0.022 & 498 & 1.18 & 1.14 \\
\hline $3 S-8 L I 60-V$ & & & $60^{\circ}$ & 0.0095 & 0.035 & 585 & 1.22 & 1.20 \\
\hline $5 S-R-V I$ & & & - & 0.0143 & 0 & 410 & 1.11 & 1.05 \\
\hline $5 S-5 L I 45-V I$ & & & $45^{\circ}$ & 0.0143 & 0.025 & 560 & 1.12 & 1.12 \\
\hline $5 S-9 L I 45-V I$ & & & $45^{\circ}$ & 0.0143 & 0.041 & 627 & 0.99 & 1.03 \\
\hline $5 S-5 L I 60-V I$ & & & $60^{\circ}$ & 0.0143 & 0.022 & 556 & 1.17 & 1.16 \\
\hline $5 S-8 L I 60-V I$ & & & $60^{\circ}$ & 0.0143 & 0.035 & 655 & 1.24 & 1.24 \\
\hline \multicolumn{9}{|c|}{ Chaallal et al. (2011) } \\
\hline SO-CON-I & \multirow{4}{*}{25.0} & \multirow{4}{*}{304.0} & - & 0 & 0 & 122 & 1.01 & 0.99 \\
\hline S1-CON-I & & & - & 0.0812 & 0 & 351 & 1.03 & 1.07 \\
\hline SO-NSM-I & & & $90^{\circ}$ & 0 & 0.54 & 331 & 1.51 & 1.13 \\
\hline S1-NSM-I & & & $90^{\circ}$ & 0.0812 & 0.54 & 356 & 1.01 & 0.98 \\
\hline S3-CON-II & \multirow{2}{*}{35.0} & \multirow{2}{*}{217.1} & - & 0.0386 & 0 & 295 & 0.98 & 0.98 \\
\hline S3-NSM-II & & & $90^{\circ}$ & 0.0386 & 0.39 & 306 & 1.11 & 1.04 \\
\hline \multicolumn{9}{|c|}{ De Lorenzis and Nanni (2001) } \\
\hline$B V$ & \multirow{7}{*}{31.0} & \multirow{7}{*}{154.8} & - & 0 & 0 & 181 & 1.13 & 1.09 \\
\hline$B 90-7$ & & & $90^{\circ}$ & 0 & 0.31 & 230 & 1.43 & 1.08 \\
\hline$B 90-5$ & & & $90^{\circ}$ & 0 & 0.44 & 255 & 1.38 & 1.07 \\
\hline$B 45-7$ & & & $45^{\circ}$ & 0 & 0.45 & 331 & 1.25 & 1.07 \\
\hline$B 45-5$ & & & $45^{\circ}$ & 0 & 0.63 & 356 & 1.43 & 1.02 \\
\hline$B S V$ & & & - & 0.029 & 0 & 306 & 1.05 & 1.12 \\
\hline$B S 90-7 A$ & & & $90^{\circ}$ & 0.029 & 0.31 & 414 & 1.33 & 1.27 \\
\hline
\end{tabular}




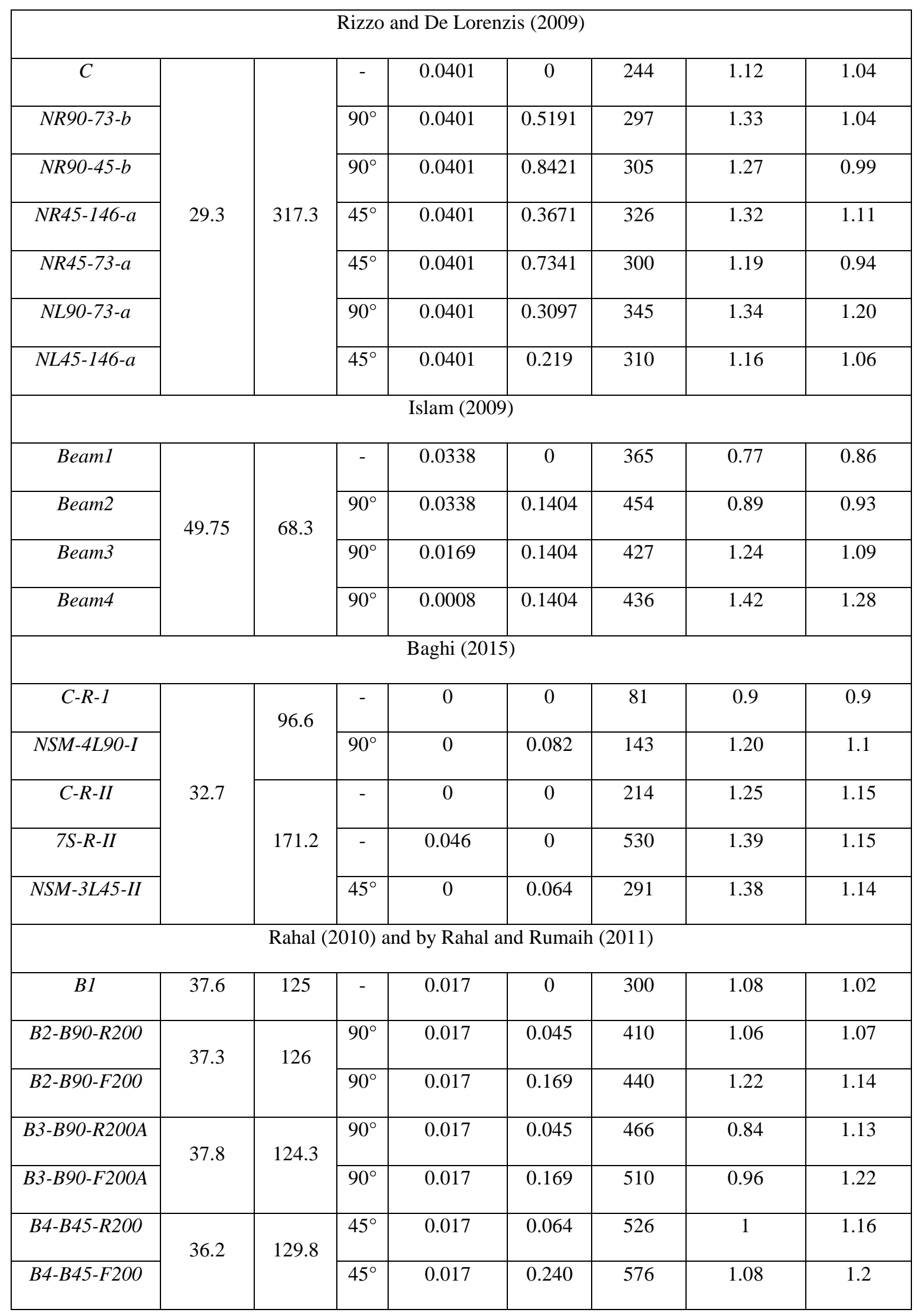




\begin{tabular}{|c|c|c|c|c|c|c|c|c|}
\hline B6-B45-R300 & \multirow{2}{*}{37.2} & \multirow{2}{*}{126.3} & $45^{\circ}$ & 0.017 & 0.042 & 380 & 0.81 & 0.98 \\
\hline B6-B45-F300 & & & $45^{\circ}$ & 0.017 & 0.160 & 410 & 0.83 & 1.01 \\
\hline \multicolumn{9}{|c|}{ Cisneros et al. (2012) } \\
\hline Control & 27.97 & 150 & - & 0.015 & 0 & 113 & 1.05 & 0.78 \\
\hline$B 90-6 a$ & 26.69 & 157 & $90^{\circ}$ & 0.016 & 0.41 & 170 & 1.11 & 1.05 \\
\hline$B 90-6 b$ & 24.09 & 174 & $90^{\circ}$ & 0.017 & 0.45 & 163 & 1.12 & 1.06 \\
\hline$B 90-3 a$ & 22.84 & 183 & $90^{\circ}$ & 0.018 & 0.24 & 117 & 0.98 & 0.84 \\
\hline$B 90-3 b$ & 26.02 & 161 & $90^{\circ}$ & 0.016 & 0.21 & 117 & 0.94 & 0.79 \\
\hline$B 45-6 a$ & 22.98 & 182 & $45^{\circ}$ & 0.018 & 0.67 & 180 & 1.07 & 1.08 \\
\hline$B 45-6 b$ & 28.48 & 147 & $45^{\circ}$ & 0.015 & 0.54 & 212 & 1.11 & 1.15 \\
\hline$B 45-3 a$ & 29.11 & 144 & $45^{\circ}$ & 0.015 & 0.26 & 189 & 1.11 & 1.06 \\
\hline$B 45-3 b$ & 23.91 & 175 & $45^{\circ}$ & 0.018 & 0.32 & 155 & 1.01 & 0.95 \\
\hline $590-6 a$ & 26.69 & 157 & $90^{\circ}$ & 0.015 & 0.30 & 189 & 1.18 & 1.17 \\
\hline$S 90-6 b$ & 24.09 & 174 & $90^{\circ}$ & 0.017 & 0.34 & 147 & 0.98 & 0.95 \\
\hline $590-3 a$ & 22.84 & 183 & $90^{\circ}$ & 0.018 & 0.18 & 117 & 0.96 & 0.84 \\
\hline$S 90-3 b$ & 26.02 & 161 & $90^{\circ}$ & 0.016 & 0.16 & 131 & 1.01 & 0.89 \\
\hline$S 45-6 a$ & 22.98 & 182 & $45^{\circ}$ & 0.018 & 0.50 & 183 & 1.05 & 1.09 \\
\hline$S 45-6 b$ & 28.48 & 147 & $45^{\circ}$ & 0.014 & 0.40 & 221 & 1.12 & 1.19 \\
\hline$S 45-3 a$ & 29.11 & 144 & $45^{\circ}$ & 0.014 & 0.20 & 206 & 1.17 & 1.16 \\
\hline$S 45-3 b$ & 23.91 & 175 & $45^{\circ}$ & 0.017 & 0.24 & 173 & 1.09 & 1.06 \\
\hline & & & & & & Average & 1.14 & 1.09 \\
\hline & & & & & & $S D$ & 0.15 & 0.12 \\
\hline & & & & & & $\mathrm{COV}$ & $13.1 \%$ & $11.0 \%$ \\
\hline
\end{tabular}


Table 3: Demerit points classification criteria

\begin{tabular}{|l|l|c|}
\hline$\lambda=V_{\text {exp. }} / \mathrm{V}_{\text {ana. }}$ & Classification & Penalty \\
\hline$<0.5$ & Extremely Dangerous & 10 \\
\hline$[0.5-0.85[$ & Dangerous & 5 \\
\hline$[0.85-1.15[$ & Appropriate Safety & 0 \\
\hline$[1.15-2[$ & Conservative & 1 \\
\hline$\geq 2.0$ & Extremely Conservative & 2 \\
\hline
\end{tabular}


Table 4: Predictive performance of different approaches according to the modified version of the DPC

\begin{tabular}{|c|c|c|c|c|}
\hline \multirow{2}{*}{$\lambda=V_{\text {exp. }} / \mathrm{V}_{\text {ana. }}$} & \multicolumn{2}{|c|}{ SBBB } & \multicolumn{2}{c|}{ TBB } \\
\cline { 2 - 5 } & $N^{o}$ samples & Total & $N^{o}$ samples & Total \\
\hline$<0.5$ & 0 & 0 & 0 & 0 \\
\hline$[0.5-0.85[$ & 4 & 20 & 4 & 20 \\
\hline$[0.85-1.15[$ & 53 & 0 & 69 & 0 \\
\hline$[1.15-2[$ & 55 & 55 & 39 & 39 \\
\hline$\geq 2.0$ & 0 & 0 & 0 & 59 \\
\hline$\sum$ PEN & 112 & 75 & 112 & \\
\hline
\end{tabular}


Table 5: Geometrical and mechanical data of the experimental RC beams

\begin{tabular}{|c|c|c|c|c|c|c|c|c|c|c|c|c|c|c|c|c|c|c|c|}
\hline Beam label & $\begin{array}{c}b_{w} \\
(\mathrm{~mm})\end{array}$ & $\begin{array}{c}h \\
(\mathrm{~mm})\end{array}$ & $\begin{array}{c}h_{w} \\
(\mathrm{~mm})\end{array}$ & $\begin{array}{c}d \\
(\mathrm{~mm})\end{array}$ & $a / d$ & $\begin{array}{c}f_{c}^{\prime} \\
(\mathrm{MPa})\end{array}$ & $\begin{array}{l}f_{l \text { yield }} \\
(\mathrm{MPa})\end{array}$ & $\begin{array}{l}\rho_{s l} \\
(\%)\end{array}$ & $\begin{array}{c}s \\
(\mathrm{~mm})\end{array}$ & $\begin{array}{l}f_{\text {y yield }} \\
(\mathrm{MPa})\end{array}$ & $\begin{array}{l}\rho_{s y} \\
(\%)\end{array}$ & $\begin{array}{l}a_{f} \times b_{f} \\
\left(\mathrm{~mm}^{2}\right)\end{array}$ & $\begin{array}{c}D_{f} \\
(\mathrm{~mm})\end{array}$ & $\theta_{f}$ & $\begin{array}{c}s_{f} \\
(\mathrm{~mm})\end{array}$ & $\begin{array}{c}E_{f} \\
(\mathrm{GPa})\end{array}$ & $\begin{array}{c}f_{f u} \\
(\mathrm{MPa})\end{array}$ & $\begin{array}{l}\varepsilon_{f u} \\
(\%)\end{array}$ & $\begin{array}{c}\mathrm{V} \\
(\mathrm{kN})\end{array}$ \\
\hline \multicolumn{20}{|c|}{ Dias and Barros $(2010 ; 2013)$} \\
\hline$C-R-I$ & \multirow{16}{*}{180} & \multirow{16}{*}{400} & \multirow{16}{*}{300} & \multirow{16}{*}{360} & \multirow{16}{*}{2.5} & \multirow{16}{*}{39.7} & \multirow{16}{*}{759} & \multirow{16}{*}{2.8} & - & - & - & \multirow{3}{*}{ - } & \multirow{16}{*}{ - } & \multirow{3}{*}{ - } & \multirow{3}{*}{ - } & \multirow{3}{*}{ - } & \multirow{3}{*}{ - } & \multirow{3}{*}{-} & 207 \\
\hline $2 S-R-I$ & & & & & & & & & 300 & \multirow{15}{*}{542} & 0.105 & & & & & & & & 304 \\
\hline $7 S-R-I$ & & & & & & & & & 112.5 & & 0.279 & & & & & & & & 467 \\
\hline $2 S-4 L V-I$ & & & & & & & & & \multirow{9}{*}{300} & & \multirow{9}{*}{0.105} & \multirow{9}{*}{13.3} & & $90^{\circ}$ & 180 & \multirow{9}{*}{218.4} & \multirow{9}{*}{2863} & \multirow{9}{*}{1.33} & 337 \\
\hline $2 S-7 L V-I$ & & & & & & & & & & & & & & $90^{\circ}$ & 114 & & & & 374 \\
\hline $2 S-10 L V-I$ & & & & & & & & & & & & & & $90^{\circ}$ & 80 & & & & 397 \\
\hline $2 S-4 L I 45-I$ & & & & & & & & & & & & & & $45^{\circ}$ & 275 & & & & 393 \\
\hline $2 S-7 L I 45-I$ & & & & & & & & & & & & & & $45^{\circ}$ & 157 & & & & 422 \\
\hline $2 S-10 L I 45-I$ & & & & & & & & & & & & & & $45^{\circ}$ & 110 & & & & 446 \\
\hline $2 S-4 L I 60-I$ & & & & & & & & & & & & & & $60^{\circ}$ & 243 & & & & 386 \\
\hline $2 S-6 L I 60-I$ & & & & & & & & & & & & & & $60^{\circ}$ & 162 & & & & 394 \\
\hline 2S-9LI60-I & & & & & & & & & & & & & & $60^{\circ}$ & 108 & & & & 413 \\
\hline $4 S-R-I I$ & & & & & & & & & & & & - & & - & - & - & - & - & 371 \\
\hline $4 S-4 L V-I I$ & & & & & & & & & & & & & & $90^{\circ}$ & 180 & & & & 424 \\
\hline $4 S-7 L V-I I$ & & & & & & & & & 180 & & 0.175 & 13.3 & & $90^{\circ}$ & 114 & 218.4 & 2863 & 1.33 & 427 \\
\hline $4 S-4 L I 45-I I$ & & & & & & & & & & & & & & $45^{\circ}$ & 275 & & & & 442 \\
\hline
\end{tabular}




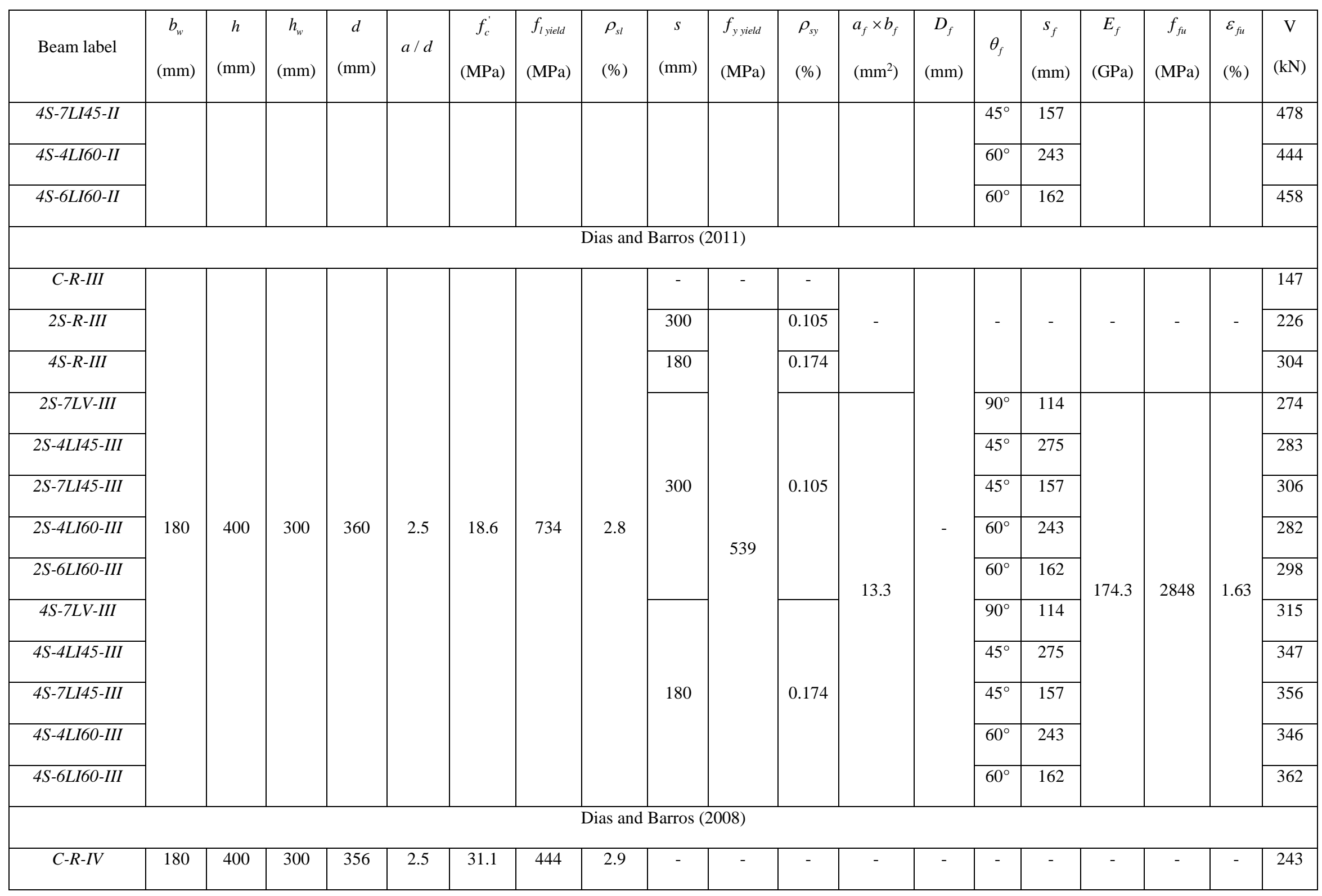




\begin{tabular}{|c|c|c|c|c|c|c|c|c|c|c|c|c|c|c|c|c|c|c|c|}
\hline Beam label & $\begin{array}{c}b_{w} \\
(\mathrm{~mm})\end{array}$ & $\begin{array}{c}h \\
(\mathrm{~mm})\end{array}$ & $\begin{array}{c}h_{w} \\
(\mathrm{~mm})\end{array}$ & $\begin{array}{c}d \\
(\mathrm{~mm})\end{array}$ & $a / d$ & $\begin{array}{c}f_{c}^{\prime} \\
(\mathrm{MPa})\end{array}$ & $\begin{array}{l}f_{\text {lyield }} \\
(\mathrm{MPa})\end{array}$ & $\begin{array}{l}\rho_{s l} \\
(\%)\end{array}$ & $\begin{array}{c}s \\
(\mathrm{~mm})\end{array}$ & $\begin{array}{l}f_{y \text { yield }} \\
(\mathrm{MPa})\end{array}$ & $\begin{array}{l}\rho_{s y} \\
(\%)\end{array}$ & $\begin{array}{c}a_{f} \times b_{f} \\
\left(\mathrm{~mm}^{2}\right)\end{array}$ & $\begin{array}{c}D_{f} \\
(\mathrm{~mm})\end{array}$ & $\theta_{f}$ & $\begin{array}{c}s_{f} \\
(\mathrm{~mm})\end{array}$ & $\begin{array}{c}E_{f} \\
(\mathrm{GPa})\end{array}$ & $\begin{array}{c}f_{f u} \\
(\mathrm{MPa})\end{array}$ & $\begin{array}{l}\varepsilon_{f u} \\
(\%)\end{array}$ & $\begin{array}{c}\mathrm{V} \\
(\mathrm{kN})\end{array}$ \\
\hline $2 S-R-I V$ & & & & & & & & & 300 & & 0.105 & & & & & & & & 315 \\
\hline $6 S-R-I V$ & & & & & & & & & 130 & & 0.241 & & & & & & & & 410 \\
\hline $2 S-3 L V-I V$ & & & & & & & & & & & & & & $90^{\circ}$ & 267 & & & & 316 \\
\hline $2 S-5 L V-I V$ & & & & & & & & & & & & & & $90^{\circ}$ & 160 & & & & 357 \\
\hline $2 S-8 L V-I V$ & & & & & & & & & & & & & & $90^{\circ}$ & 100 & & & & 396 \\
\hline $2 S-3 L I 45-I V$ & & & & & & & & & & 533 & & & & $45^{\circ}$ & 367 & & & & 328 \\
\hline $2 S-5 L I 45-I V$ & & & & & & & & & 300 & & 0.241 & 14 & & $45^{\circ}$ & 220 & 166.6 & 2952 & 1.77 & 384 \\
\hline $2 S-8 L I 45-I V$ & & & & & & & & & & & & & & $45^{\circ}$ & 138 & & & & 382 \\
\hline $2 S-3 L I 60-I V$ & & & & & & & & & & & & & & $60^{\circ}$ & 325 & & & & 374 \\
\hline $2 S-5 L I 60-I V$ & & & & & & & & & & & & & & $60^{\circ}$ & 195 & & & & 392 \\
\hline $2 S-7 L I 60-I V$ & & & & & & & & & & & & & & $60^{\circ}$ & 139 & & & & 406 \\
\hline & & & & & & & & & $(2008)$ & & & & & & & & & & \\
\hline$C-R-V$ & \multirow{7}{*}{180} & \multirow{7}{*}{400} & \multirow{7}{*}{300} & \multirow{7}{*}{360} & \multirow{7}{*}{3.33} & \multirow{7}{*}{59.4} & \multirow{7}{*}{716} & \multirow{7}{*}{3.1} & - & - & - & - & & & & & & & 252 \\
\hline $3 S-R-V$ & & & & & & & & & \multirow{6}{*}{300} & \multirow{6}{*}{551} & \multirow{6}{*}{0.105} & \multirow{6}{*}{13.3} & & - & & & & - & 360 \\
\hline $3 S-6 L V-V$ & & & & & & & & & & & & & & $90^{\circ}$ & 180 & \multirow{5}{*}{174.3} & \multirow{5}{*}{2848} & \multirow{5}{*}{16.3} & 387 \\
\hline $3 S-10 L V-V$ & & & & & & & & & & & & & - & $90^{\circ}$ & 114 & & & & 497 \\
\hline $3 S-5 L I 45-V$ & & & & & & & & & & & & & & $45^{\circ}$ & 275 & & & & 492 \\
\hline $3 S-9 L I 45-V$ & & & & & & & & & & & & & & $45^{\circ}$ & 157 & & & & 564 \\
\hline $3 S-5 L I 60-V$ & & & & & & & & & & & & & & $60^{\circ}$ & 243 & & & & 498 \\
\hline
\end{tabular}




\begin{tabular}{|c|c|c|c|c|c|c|c|c|c|c|c|c|c|c|c|c|c|c|c|}
\hline Beam label & $\begin{array}{c}b_{w} \\
(\mathrm{~mm})\end{array}$ & $\begin{array}{c}h \\
(\mathrm{~mm})\end{array}$ & $\begin{array}{c}h_{w} \\
(\mathrm{~mm})\end{array}$ & $\begin{array}{c}d \\
(\mathrm{~mm})\end{array}$ & $a / d$ & $\begin{array}{c}f_{c}^{\prime} \\
(\mathrm{MPa})\end{array}$ & $\begin{array}{l}f_{\text {lyield }} \\
(\mathrm{MPa})\end{array}$ & $\begin{array}{l}\rho_{s l} \\
(\%)\end{array}$ & $\begin{array}{c}s \\
(\mathrm{~mm})\end{array}$ & $\begin{array}{l}f_{y \text { yield }} \\
(\mathrm{MPa})\end{array}$ & $\begin{array}{l}\rho_{s y} \\
(\%)\end{array}$ & $\begin{array}{l}a_{f} \times b_{f} \\
\left(\mathrm{~mm}^{2}\right)\end{array}$ & $\begin{array}{c}D_{f} \\
(\mathrm{~mm})\end{array}$ & $\theta_{f}$ & $\begin{array}{c}s_{f} \\
(\mathrm{~mm})\end{array}$ & $\begin{array}{c}E_{f} \\
(\mathrm{GPa})\end{array}$ & $\begin{array}{c}f_{f u} \\
(\mathrm{MPa})\end{array}$ & $\begin{array}{l}\varepsilon_{f u} \\
(\%)\end{array}$ & $\begin{array}{c}\mathrm{V} \\
(\mathrm{kN})\end{array}$ \\
\hline $3 S-8 L I 60-V$ & & & & & & & & & & & & & & $60^{\circ}$ & 162 & & & & 585 \\
\hline $5 S-R-V I$ & & & & & & & & & & & & - & & - & - & - & - & - & 410 \\
\hline $5 S-5 L I 45-V I$ & & & & & & & & & & & & & & $45^{\circ}$ & 275 & & & & 560 \\
\hline 5S-9LI45-VI & & & & & & & & & 200 & & 0.157 & & & $45^{\circ}$ & 157 & & & & 627 \\
\hline $5 S-5 L I 60-V I$ & & & & & & & & & & & & & & $60^{\circ}$ & 243 & 17т. & 2070 & 10.0 & 556 \\
\hline 5S-8LI60-VI & & & & & & & & & & & & & & $60^{\circ}$ & 162 & & & & 655 \\
\hline & & & & & & & & Chaall & et al. (2 & & & & & & & & & & \\
\hline SO-CON-I & \multirow{8}{*}{152} & \multirow{8}{*}{406} & \multirow{8}{*}{304} & \multirow{8}{*}{350} & \multirow{8}{*}{3} & \multirow{5}{*}{25} & \multirow{5}{*}{470} & \multirow{8}{*}{3.7} & - & - & - & \multirow{8}{*}{ - } & \multirow{3}{*}{ - } & \multirow{2}{*}{ - } & \multirow{2}{*}{ - } & \multirow{3}{*}{ - } & \multirow{3}{*}{ - } & \multirow{2}{*}{ - } & 122 \\
\hline S1-CON-I & & & & & & & & & 175 & 540 & 0.376 & & & & & & & & 351 \\
\hline & & & & & & & & & & & & & & & & & & & \\
\hline$S O-N S M-I$ & & & & & & & & & - & - & - & & \multirow[t]{2}{*}{9.5} & \multirow[t]{2}{*}{$90^{\circ}$} & 130 & \multirow[t]{2}{*}{148} & \multirow[t]{2}{*}{1885} & \multirow[t]{2}{*}{1.27} & 331 \\
\hline S1-NSM-I & & & & & & & & & 175 & 540 & 0.376 & & & & 130 & & & & 356 \\
\hline S3-CON-II & & & & & & \multirow{3}{*}{35} & \multirow{3}{*}{650} & & \multirow{3}{*}{262.5} & \multirow{3}{*}{650} & \multirow{3}{*}{0.251} & & - & - & - & - & - & - & 295 \\
\hline & & & & & & & & & & & & & 95 & $90^{\circ}$ & 130 & 148 & 1885 & 127 & 306 \\
\hline S3-NSM-II & & & & & & & & & & & & & & & & & & & \\
\hline \multicolumn{20}{|c|}{ De Lorenzis and Nanni (2001) } \\
\hline$B V$ & \multirow{5}{*}{152} & \multirow{5}{*}{406} & & & & & & & & & & & - & - & - & - & - & - & 181 \\
\hline B90-7 & & & & & & & & & & & & & & $90^{\circ}$ & 178 & & & & 230 \\
\hline$B 90-5$ & & & 304 & 356 & 3 & 31 & 414 & 2.4 & - & - & - & - & & $90^{\circ}$ & 127 & & & & 255 \\
\hline B45-7 & & & & & & & & & & & & & & $45^{\circ}$ & 178 & & & & 331 \\
\hline$B 45-5$ & & & & & & & & & & & & & & $45^{\circ}$ & 127 & & & & 356 \\
\hline
\end{tabular}




\begin{tabular}{|c|c|c|c|c|c|c|c|c|c|c|c|c|c|c|c|c|c|c|c|}
\hline Beam label & $\begin{array}{c}b_{w} \\
(\mathrm{~mm})\end{array}$ & $\begin{array}{c}h \\
(\mathrm{~mm})\end{array}$ & $\begin{array}{c}h_{w} \\
(\mathrm{~mm})\end{array}$ & $\begin{array}{c}d \\
(\mathrm{~mm})\end{array}$ & $a / d$ & $\begin{array}{c}f_{c}^{\prime} \\
(\mathrm{MPa})\end{array}$ & $\begin{array}{l}f_{l \text { yield }} \\
(\mathrm{MPa})\end{array}$ & $\begin{array}{l}\rho_{s l} \\
(\%)\end{array}$ & $\begin{array}{c}s \\
(\mathrm{~mm})\end{array}$ & $\begin{array}{l}f_{\text {y yield }} \\
(\mathrm{MPa})\end{array}$ & $\begin{array}{c}\rho_{s y} \\
(\%)\end{array}$ & $\begin{array}{l}a_{f} \times b_{f} \\
\left(\mathrm{~mm}^{2}\right)\end{array}$ & $\begin{array}{c}D_{f} \\
(\mathrm{~mm})\end{array}$ & $\theta_{f}$ & $\begin{array}{c}s_{f} \\
(\mathrm{~mm})\end{array}$ & $\begin{array}{c}E_{f} \\
(\mathrm{GPa})\end{array}$ & $\begin{array}{c}f_{f u} \\
(\mathrm{MPa})\end{array}$ & $\begin{array}{l}\varepsilon_{f u} \\
(\%)\end{array}$ & $\begin{array}{c}\mathrm{V} \\
(\mathrm{kN})\end{array}$ \\
\hline$B S V$ & & & & & & & & & & & & & - & - & - & - & - & - & 306 \\
\hline BS90-7A & & & & & & & & & & & & & 9.5 & $90^{\circ}$ & 178 & $\begin{array}{l}104.8 \\
\end{array}$ & 1875 & 1.79 & 414 \\
\hline & & & & & & & & and & Lorenz & S(2009) & & & & & & & & & \\
\hline$C$ & \multirow{7}{*}{200} & \multirow{7}{*}{210} & \multirow{7}{*}{210} & \multirow{7}{*}{173} & \multirow{7}{*}{3} & \multirow{7}{*}{29.3} & \multirow{7}{*}{544} & \multirow{7}{*}{4.4} & \multirow{7}{*}{160} & \multirow{7}{*}{665.3} & \multirow{7}{*}{0.177} & - & - & - & - & - & - & - & 244 \\
\hline$N R 90-73-b$ & & & & & & & & & & & & \multirow{4}{*}{ - } & \multirow{4}{*}{8} & $90^{\circ}$ & 73 & \multirow{4}{*}{145.7} & \multirow{4}{*}{2214} & \multirow{4}{*}{1.52} & 297 \\
\hline$N R 90-45-b$ & & & & & & & & & & & & & & $90^{\circ}$ & 45 & & & & 305 \\
\hline NR45-146- $a$ & & & & & & & & & & & & & & $45^{\circ}$ & 146 & & & & 326 \\
\hline$N R 45-73-a$ & & & & & & & & & & & & & & $45^{\circ}$ & 73 & & & & 300 \\
\hline$N L 90-73-a$ & & & & & & & & & & & & \multirow[b]{2}{*}{32} & & $90^{\circ}$ & 73 & \multirow[b]{2}{*}{121.5} & \multirow[b]{2}{*}{2068} & \multirow[b]{2}{*}{1.7} & 345 \\
\hline NL45-146- $a$ & & & & & & & & & & & & & & $45^{\circ}$ & 146 & & & & 310 \\
\hline \multicolumn{20}{|c|}{ Islam (2009) } \\
\hline Beaml & \multirow{5}{*}{254} & \multirow{5}{*}{305} & \multirow{5}{*}{305} & \multirow{5}{*}{261} & \multirow{5}{*}{2.34} & \multirow{5}{*}{49.75} & \multirow{5}{*}{414} & & 152 & & 0.34 & & - & - & - & - & - & - & 365 \\
\hline Beam2 & & & & & & & & & 152 & & 0.34 & & & $90^{\circ}$ & 152 & & & & 454 \\
\hline & & & & & & & & 1.7 & & 414 & & - & & & & & & & \\
\hline Beam3 & & & & & & & & & 305 & & 0.168 & & 9 & $90^{\circ}$ & 305 & 124 & 2068 & 1.66 & 427 \\
\hline Beam4 & & & & & & & & & 610 & & 0.085 & & & $90^{\circ}$ & 152 & & & & 436 \\
\hline & & & & & & & & & i (2015 & & & & & & & & & & \\
\hline$C-R-1$ & & & & & & & & & & & & - & & - & - & - & - & - & 81 \\
\hline NSM-4L90-I & 150 & 300 & 300 & 264 & 3 & 32.7 & 580 & 1.6 & - & - & - & 14 & - & $90^{\circ}$ & 180 & 150 & 2620 & 1.6 & 143 \\
\hline$C-R-I I$ & 180 & 400 & 300 & 360 & 2.5 & & 625 & 2.8 & - & - & - & - & & - & - & - & - & - & 214 \\
\hline
\end{tabular}




\begin{tabular}{|c|c|c|c|c|c|c|c|c|c|c|c|c|c|c|c|c|c|c|c|}
\hline Beam label & $\begin{array}{c}b_{w} \\
(\mathrm{~mm})\end{array}$ & $\begin{array}{c}h \\
(\mathrm{~mm})\end{array}$ & $\begin{array}{c}h_{w} \\
(\mathrm{~mm})\end{array}$ & $\begin{array}{c}d \\
(\mathrm{~mm})\end{array}$ & $a / d$ & $\begin{array}{c}f_{c}^{\prime} \\
(\mathrm{MPa})\end{array}$ & $\begin{array}{l}f_{\text {lyield }} \\
(\mathrm{MPa})\end{array}$ & $\begin{array}{l}\rho_{s l} \\
(\%)\end{array}$ & $\begin{array}{c}s \\
(\mathrm{~mm})\end{array}$ & $\begin{array}{l}f_{\text {y yield }} \\
(\mathrm{MPa})\end{array}$ & $\begin{array}{c}\rho_{s y} \\
(\%)\end{array}$ & $\begin{array}{l}a_{f} \times b_{f} \\
\left(\mathrm{~mm}^{2}\right)\end{array}$ & $\begin{array}{c}D_{f} \\
(\mathrm{~mm})\end{array}$ & $\theta_{f}$ & $\begin{array}{c}s_{f} \\
(\mathrm{~mm})\end{array}$ & $\begin{array}{c}E_{f} \\
(\mathrm{GPa})\end{array}$ & $\begin{array}{c}f_{f u} \\
(\mathrm{MPa})\end{array}$ & $\begin{array}{l}\varepsilon_{f u} \\
(\%)\end{array}$ & $\begin{array}{c}\mathrm{V} \\
(\mathrm{kN})\end{array}$ \\
\hline $7 S-R-I I$ & & & & & & & & & 112.5 & 500 & 0.279 & & & - & - & & & & 530 \\
\hline NSM-3L45-II & & & & & & & & & - & - & - & 14 & & $45^{\circ}$ & 275 & 150 & 2620 & 1.6 & 291 \\
\hline & & & & & & & hal (201 & and $b$ & Rahal a & Rumail & $(2011)$ & & & & & & & & \\
\hline$B 1$ & \multirow{9}{*}{150} & \multirow{9}{*}{500} & \multirow{9}{*}{400} & \multirow{9}{*}{430} & \multirow{9}{*}{3} & 37.6 & \multirow{9}{*}{446} & \multirow{9}{*}{2.35} & \multirow{7}{*}{200} & \multirow{9}{*}{338} & \multirow{7}{*}{0.188} & \multirow{9}{*}{ - } & - & - & - & - & - & - & 300 \\
\hline$B 2-B 90-R 200$ & & & & & & & & & & & & & \multirow{8}{*}{8} & $90^{\circ}$ & 200 & 210 & 510 & 0.24 & 410 \\
\hline$B 2-B 90-F 200$ & & & & & & & & & & & & & & $90^{\circ}$ & 200 & 124 & 1900 & 1.53 & 440 \\
\hline$B 3-B 90-R 200 A$ & & & & & & & & & & & & & & $90^{\circ}$ & 200 & 210 & 510 & 0.24 & 466 \\
\hline$B 3-B 90-F 200 A$ & & & & & & & & & & & & & & $90^{\circ}$ & 200 & 124 & 1900 & 1.53 & 510 \\
\hline$B 4-B 45-R 200$ & & & & & & \multirow{2}{*}{36.2} & & & & & & & & $45^{\circ}$ & 200 & 210 & 510 & 0.24 & 526 \\
\hline$B 4-B 45-F 200$ & & & & & & & & & & & & & & $45^{\circ}$ & 200 & 124 & 1900 & 1.53 & 576 \\
\hline$B 6-B 45-R 300$ & & & & & & \multirow[b]{2}{*}{37.2} & & & \multirow[b]{2}{*}{300} & & \multirow[b]{2}{*}{0.126} & & & $45^{\circ}$ & 300 & 210 & 510 & 0.24 & 380 \\
\hline & & & & & & & & & & & & & & & 300 & 124 & 1900 & 153 & 410 \\
\hline \multicolumn{20}{|c|}{ Cisneros et al. (2012) } \\
\hline Control & \multirow{7}{*}{200} & \multirow{6}{*}{350} & \multirow{6}{*}{350} & \multirow{7}{*}{310} & \multirow{7}{*}{3} & 27.97 & \multirow{6}{*}{446} & \multirow{6}{*}{2.0} & \multirow{6}{*}{230} & \multirow{7}{*}{338} & \multirow{7}{*}{0.123} & \multirow{6}{*}{-} & - & - & - & - & - & - & 113 \\
\hline B90-6a & & & & & & 26.69 & & & & & & & & $90^{\circ}$ & 115 & \multirow{5}{*}{165} & & & 170 \\
\hline$B 90-6 b$ & & & & & & 24.09 & & & & & & & & $90^{\circ}$ & 115 & & & & 163 \\
\hline$B 90-3 a$ & & & & & & 2284 & & & & & & & 8 & $90^{\circ}$ & 230 & & 2500 & 151 & 117 \\
\hline$B 90-3 b$ & & & & & & 26.02 & & & & & & & & $90^{\circ}$ & 230 & & & & 117 \\
\hline$B 45-6 a$ & & & & & & 22.98 & & & & & & & & $45^{\circ}$ & 115 & & & & 180 \\
\hline & & & & & & & & & & & & & & & & & & & \\
\hline
\end{tabular}




\begin{tabular}{|c|c|c|c|c|c|c|c|c|c|c|c|c|c|c|c|c|c|c|c|}
\hline Beam label & $\begin{array}{c}b_{w} \\
(\mathrm{~mm})\end{array}$ & $\begin{array}{c}h \\
(\mathrm{~mm})\end{array}$ & $\begin{array}{c}h_{w} \\
(\mathrm{~mm})\end{array}$ & $\begin{array}{c}d \\
(\mathrm{~mm})\end{array}$ & $a / d$ & $\begin{array}{c}f_{c}^{\prime} \\
\text { (MPa) }\end{array}$ & $\begin{array}{l}f_{\text {lyield }} \\
\text { (MPa) }\end{array}$ & $\begin{array}{l}\rho_{s l} \\
(\%)\end{array}$ & $\begin{array}{c}s \\
(\mathrm{~mm})\end{array}$ & $\begin{array}{l}f_{\text {y yield }} \\
\text { (MPa) }\end{array}$ & $\begin{array}{l}\rho_{s y} \\
(\%)\end{array}$ & $\begin{array}{l}a_{f} \times b_{f} \\
\left(\mathrm{~mm}^{2}\right)\end{array}$ & $\begin{array}{c}D_{f} \\
(\mathrm{~mm})\end{array}$ & $\theta_{f}$ & $\begin{array}{c}s_{f} \\
(\mathrm{~mm})\end{array}$ & $\begin{array}{c}E_{f} \\
(\mathrm{GPa})\end{array}$ & $\begin{array}{c}f_{f u} \\
\text { (MPa) }\end{array}$ & $\begin{array}{l}\varepsilon_{f u} \\
(\%)\end{array}$ & $\begin{array}{c}\mathrm{V} \\
(\mathrm{kN})\end{array}$ \\
\hline$B 45-6 b$ & & & & & & 28.48 & & & & & & & & $45^{\circ}$ & 115 & & & & 212 \\
\hline$B 45-3 a$ & & & & & & 29.11 & & & & & & & & $45^{\circ}$ & 230 & & & & 189 \\
\hline$B 45-3 b$ & & & & & & 23.91 & & & & & & & & $45^{\circ}$ & 230 & & & & 155 \\
\hline$S 90-6 a$ & & & & & & 26.69 & & & & & & & & $90^{\circ}$ & 115 & & & & 189 \\
\hline$S 90-6 b$ & & & & & & 24.09 & & & & & & & & $90^{\circ}$ & 115 & & & & 147 \\
\hline$S 90-3 a$ & & & & & & 22.84 & & & & & & & & $90^{\circ}$ & 230 & & & & 117 \\
\hline$S 90-3 b$ & & & & & & 26.02 & & & & & & & & $90^{\circ}$ & 230 & & & & 131 \\
\hline$S 45-6 a$ & & & & & & 22.98 & & & & & & & & $45^{\circ}$ & 115 & & & & 183 \\
\hline$S 45-6 b$ & & & & & & 28.48 & & & & & & & & $45^{\circ}$ & 115 & & & & 221 \\
\hline $545-3 a$ & & & & & & 29.11 & & & & & & & & $45^{\circ}$ & 230 & & & & 206 \\
\hline$S 45-3 b$ & & & & & & 23.91 & & & & & & & & $45^{\circ}$ & 230 & & & & 173 \\
\hline
\end{tabular}


1

\begin{tabular}{|c|c|c|c|c|c|c|c|c|c|c|}
\hline \multirow{2}{*}{ Iteration } & $\begin{array}{c}A=\varepsilon_{x} \\
\text { Estimated }\end{array}$ & $S_{x e}$ & $\beta$ & $\theta$ & $v_{c}$ & $v_{s}$ & $v_{f}$ & $v$ & $B=\varepsilon_{x}$ & $A-B$ \\
\hline 1 & 0.001 & 276.58 & 0.1629 & 35.66 & 1.03 & 0.79 & 0.84 & 2.66 & $4.55 \mathrm{e}-4$ & $5.45 \mathrm{e}-4$ \\
\hline 2 & $5.11 \mathrm{e}-4$ & 276.58 & 0.2307 & 32.27 & 1.45 & 0.90 & 0.95 & 3.30 & $7.43 \mathrm{e}-4$ & $-2.32 \mathrm{e}-4$ \\
\hline 3 & $7.43 \mathrm{e}-4$ & 276.58 & 0.1926 & 33.88 & 1.21 & 0.84 & 0.90 & 2.95 & $6.17 \mathrm{e}-4$ & $1.26 \mathrm{e}-4$ \\
\hline 4 & $6.17 \mathrm{e}-4$ & 276.58 & 0.2115 & 33.01 & 1.33 & 0.87 & 0.93 & 3.13 & $6.81 \mathrm{e}-4$ & $-6.40 \mathrm{e}-5$ \\
\hline 5 & $6.81 \mathrm{e}-4$ & 276.58 & 0.2015 & 33.45 & 1.27 & 0.86 & 0.91 & 3.04 & $6.48 \mathrm{e}-4$ & $3.30 \mathrm{e}-5$ \\
\hline 6 & $6.48 \mathrm{e}-4$ & 276.58 & 0.2066 & 33.22 & 1.30 & 0.87 & 0.92 & 3.09 & $6.65 \mathrm{e}-4$ & $-1.70 \mathrm{e}-5$ \\
\hline 7 & $6.65 \mathrm{e}-4$ & 276.58 & 0.2039 & 33.34 & 1.28 & 0.86 & 0.91 & 3.06 & $6.55 \mathrm{e}-4$ & $1.00 \mathrm{e}-5$ \\
\hline 8 & $6.55 \mathrm{e}-4$ & 276.58 & 0.2053 & 33.28 & 1.29 & 0.86 & 0.92 & 3.07 & $6.61 \mathrm{e}-4$ & $-6.00 \mathrm{e}-6$ \\
\hline 9 & $6.61 \mathrm{e}-4$ & 276.58 & 0.2046 & 33.31 & 1.29 & 0.86 & 0.92 & 3.07 & $6.61 \mathrm{e}-4$ & 0 \\
\hline
\end{tabular}

2 
Table 7: SBBB approach

\begin{tabular}{|c|c|c|c|c|c|}
\hline Iteration & $x=\frac{\rho_{s y} f_{\text {yyield }}}{f_{c}^{\prime}}+\frac{\rho_{f} f_{f u}}{f_{c}^{\prime}}$ & $y=\frac{\rho_{s l} E_{s l}}{f_{c}^{\prime}}$ & $\beta_{s}$ & $\theta_{s}$ & $v$ \\
\hline 1 & 0.0693 & 146.7 & 0.195 & 34.35 & 2.93 \\
\hline
\end{tabular}

27

28

29 